Utah State University

DigitalCommons@USU

$12-2012$

\title{
Relationships Between Classroom Schedule Types and Performance on the Algebra I Criterion-Referenced Test
}

Gregory V. Murray

Utah State University

Follow this and additional works at: https://digitalcommons.usu.edu/etd

Part of the Science and Mathematics Education Commons

\section{Recommended Citation}

Murray, Gregory V., "Relationships Between Classroom Schedule Types and Performance on the Algebra I Criterion-Referenced Test" (2012). All Graduate Theses and Dissertations. 1403.

https://digitalcommons.usu.edu/etd/1403

This Dissertation is brought to you for free and open access by the Graduate Studies at DigitalCommons@USU. It has been accepted for inclusion in All Graduate Theses and Dissertations by an authorized administrator of DigitalCommons@USU. For more information, please contact digitalcommons@usu.edu.

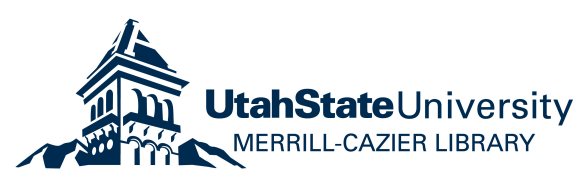




\section{RELATIONSHIPS BETWEEN CLASSROOM SCHEDULE TYPES AND}

PERFORMANCE ON THE ALGEBRA I CRITERION-

REFERENCED TEST

by

$$
\text { Gregory V. Murray }
$$

A dissertation submitted in partial fulfillment

of the requirements for the degree

of

DOCTOR OF PHILOSOPHY

in

Education

Approved:

Dr. Patricia Moyer-Packenham

Major Professor

Dr. James Cangelosi

Committee Member

Dr. Susan Turner

Committee Member
Dr. Amy Bingham Brown

Committee Member

Dr. Steven Laing

Committee Member

Dr. Mark R. McLellan

Vice President for Research and

Dean of the School of Graduate Studies

UATH STATE UNIVERSITY

Logan, UT 
Copyright (C) Gregory V. Murray 2012

All Rights Reserved 


\author{
ABSTRACT \\ Relationships Between Classroom Schedule Types and Performance on the \\ Algebra I Criterion-Referenced Test \\ by \\ Gregory V. Murray, Doctor of Philosophy \\ Utah State University, 2012 \\ Major Professor: Dr. Patricia Moyer-Packenham \\ Department: School of Teacher Education and Leadership
}

Public education has options with regard to educational settings and structures. States and school districts may select varying lengths for the school year, lengths for the school day, and lengths for individual class periods. In Utah, one measure of students’ achievement is scores on the State's end-of-level criterion-referenced test (CRT) for Algebra I. Additionally, an option regarding educational structures is the schedule type used to deliver Algebra I classes. This study examined the relationship between student achievement as measured by Algebra I CRT scores, and the schedule type used to deliver Algebra I classes. The schedule types compared were the traditional daily schedule, trimester 3/3 schedule, trimester 2/3 schedule, and the block A/B schedule. This study sought to answer two research questions: (1) What is the relationship between mathematics instructional schedule type and student scores on Utah's CRT for Algebra I, for all students? and (2) What is the relationship between mathematics instructional 
schedule type and student scores on Utah’s CRT for Algebra I, by individual grade levels? Data were obtained from the Utah State Office of Education and included the scores for 50,000 Utah students, from over 300 different schools, who took the identical Algebra I CRT at the end of the 2010-2011 school year. Data were also obtained from each school district to determine the schedule type of each participating student. Both a multinomial logistic regression analysis and a $t$-test analysis were conducted to determine relationships between Algebra I CRT scores and schedule types. The results indicated significant differences in student achievement based on the schedule type overall and for individual grade levels. Generally, the earlier the grade level the higher the CRT score. Within individual grade levels, there were both statistically significant and nonsignificant differences. The schedule types that generally score the highest (trimester 3/3 and traditional) had more time in the mathematics classroom and the students' mathematics class met daily. The results suggest the value of daily time spent in the mathematics classroom and may assist educators when considering options available to foster student achievement. 


\title{
PUBLIC ABSTRACT
}

\author{
Relationships Between Classroom Schedule Types and Performance on the \\ Algebra I Criterion-Referenced Test \\ by \\ Gregory V. Murray, Doctor of Philosophy \\ Utah State University, 2012
}

Public education has options in regard to educational settings and structures. States and school districts may select varying lengths for the school year, lengths for the school day, lengths for individual class periods, and course scheduling configurations. The No Child Left Behind Act of 2001 urged educators to improve educational outcomes while examining selected measures of student achievement. In Utah, one measure of students' achievement is scores on the state's end of level criterion-referenced test (CRT) for Algebra I. In addition, one option regarding educational structures is the schedule type used to deliver Algebra I classes. This study examined the relationship between student achievements in Algebra I, as measured by Algebra I CRT scores, and the schedule type used to deliver Algebra I classes. The schedule types compared were the traditional daily schedule, trimester $3 / 3$ schedule, trimester $2 / 3$ schedule, and the block A/B schedule. This study sought to answer two research questions: (1) Are there statistically significant differences in student CRT scores on the Algebra I test when comparing schedule types? and (2) Are there statistically significant differences in 
student CRT scores on the Algebra I test when separating students by grade level and then comparing schedule types?

Data were obtained from the Utah State Office of Education and included the scores for 50,000 Utah students, from over 300 different schools, who took the identical Algebra I CRT at the end of the 2010-2011 school year. Data were also obtained from each school district to determine the schedule type of each participating student. A multinomial logistic regression analysis was conducted, in con junction with $t$ tests for percent analysis, to determine relationships between Algebra I CRT scores and schedule types. The results indicated significant differences in student achievement based on the schedule type overall and for individual grade levels. Generally, the earlier the grade level the higher the CRT score. In grades seven, eight, and nine, the results showed the trimester 3/3 schedule students scored the highest. For grades 10 and 11, the traditional schedule students' scored the highest; and for $12^{\text {th }}$ grade there was no significant difference between scores. The schedule types that generally score the highest (trimester 3/3 and traditional) had more time in the mathematics classroom and the students' mathematics class met daily. The results demonstrate the value of daily time spent in the mathematics classroom and may assist educators when considering options available to foster student achievement. 


\section{ACKNOWLEDGMENTS}

An undertaking of this scale may be embarked upon by an individual but is accomplished through the combined efforts of many. I have profound gratitude for those who have advised, instructed, guffawed, read, reread, edited, cautioned, encouraged, and inspired. To those who have assisted along the way I dedicate this dissertation.

The faculty at Utah State University reminded me that true scholarship has no shortcuts. Dr. Steven Laing helped me remember that writings about public education are not made in a void and kept me aware of being a part in the broad community of educators. Dr. Amy Brown stepped in at the last moment and proved invaluable with her insightful questioning. Dr. Susan Turner spoke softly and carried deep understanding, insight, and kindness. Dr. Jim Cangelosi impressed me with his brash candor, statistical acumen, and unwavering dedication to what is best in mathematics education.

Most importantly, without the patience and skill of my chair, Dr. Patricia MoyerPackenham, this dissertation would have never reached fruition. Her careful presentation of the roadmap allowed me to place one foot in front of the other in the most useful directions. When we discussed the process it was always "we."

I wish to thank the faculty of Dixie State College Education Department who encouraged me to persevere in my work there and simultaneously at Utah State University. Thanks to Dr. Kyle Wells for statistical and doctoral advice. Also, without the assistance and data from the Utah State Office of Education, this work would never have been completed.

Through this process I have grown as an individual and as an educator. This 
educational journey began many years ago when my mother, Margaret, kept me on task and taught me the value of learning; and my father, Robert, worked tirelessly so that all of his children would gain what he never did, a college education. My four brothers, Martin, Mark, Dennis, and Thomas, inspired and cajoled me to continue growing. My four children, Sarah, Sam, Zach, and Anna, have had to adjust to the times that I was correcting more assignments or writing more papers. On this journey I have had a constant companion, my wife, Dee. She was always alongside as she simultaneously completed her doctoral program. It gave us something to talk about. But as we walked together for years through our programs, onward and upward, at times I carried her backpack and many times she carried mine. We have always been close to each other, now we are closer. I dedicate this work to these family members and to my educational family members as well. 


\section{CONTENTS}

ABSTRACT.

iii

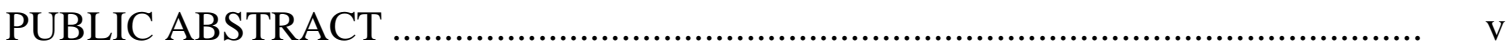

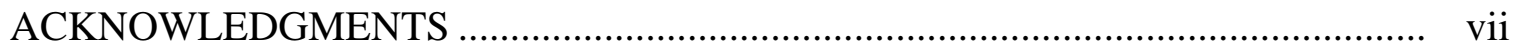

LIST OF TABLES ................................................................................ xi

\section{CHAPTER}

I. INTRODUCTION ....................................................................... 1

Background of the Problem ...................................................................... 1

Statement of the Problem.......................................................................... 2

Significance of the Problem........................................................................... 3

Definition of Terms............................................................................. 5

Purpose of the Study ........................................................................... 6

Research Questions ........................................................................ 8

Assumptions, Delimitations, and Limitations............................................. 8

II. REVIEW OF LITERATURE ........................................................ 11

Scheduling Variations in the Algebra I Classroom.................................... 11

Role of Algebra in the School Curriculum .................................................. 17

Research on Classroom Schedules, Mathematics, and Algebra I................. 19

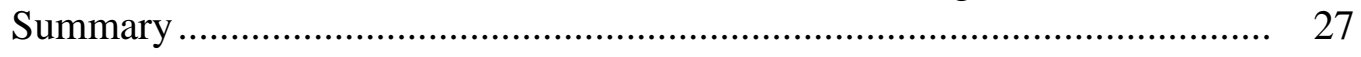

III. METHODS .............................................................................. 29

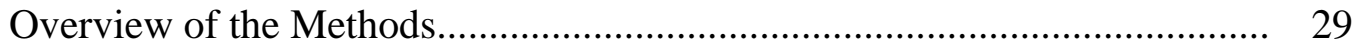

Research Questions ......................................................................... 30

Research Design................................................................................ $\quad 30$

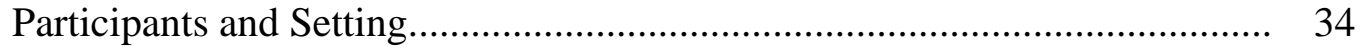

Data Sources .................................................................................. 37

Data Collection and Organization Procedures ........................................... 38

Data Analysis Using SPSS............................................................ 42 


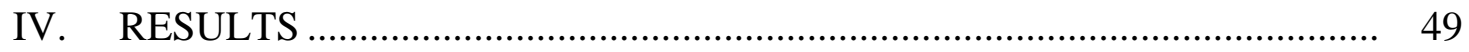

Overview of Results......................................................................... 49

Statistical Output and Analysis for Research Question 1 .......................... 52

Statistical Output and Analysis for Research Question 2 .......................... 58

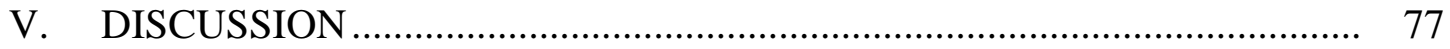

Summary ..................................................................................... 77

Discussion of the Results .................................................................... 78

Limitations, Recommendations, and Final Conclusions.............................. 85

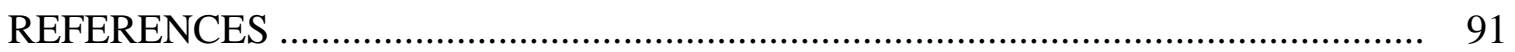

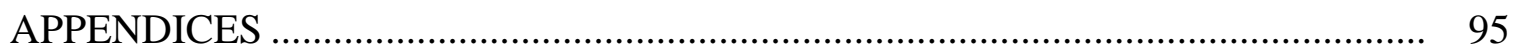

Appendix A: Institutional Review Board (IRB) Certificate ........................ 96

Appendix B: Permission to Publish State of Utah Data ............................. 98

Appendix C: Descriptors of Terms for Algebra I Proficiency Scores.......... 100

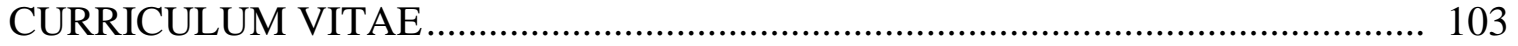




\section{LIST OF TABLES}

Table

1. Schedule Types Comparison...................................................................... 14

2. Summary of Research of Differences by Schedule Type ............................... 24

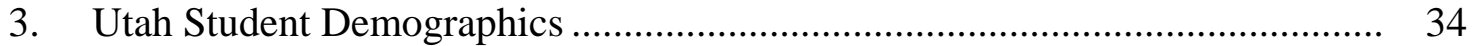

4. 2010-2011 Algebra CRT Scoring Classifications...................................... 38

5. Sample of Data Received from USOE................................................... 39

6. Sample of Cleaned Data in Excel ........................................................... 41

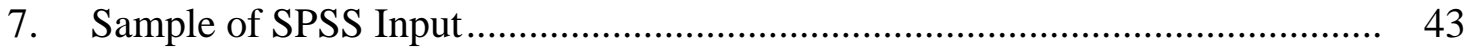

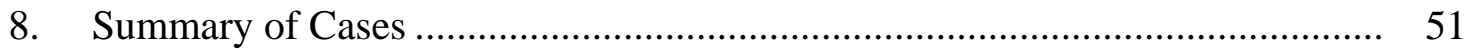

9. Summary of CRT Scores by Schedule for All Algebra Students .................... 53

10. Multinomial Logistic Regression Model Fitting, Using Schedule Type .......... 54

11. Multinomial Logistic Regression Using Schedule Type .............................. 54

12. Percentage of Students Who Passed the CRT by Grade Level....................... 59

13. Multinomial Logistic Regression Model Fitting, Using Grade Level Only ...... 60

14. Likelihood Ratio Tests for CRT Scores with Schedule Type and Grade Level

15. Multinomial Logistic Regression Using Schedule Type and Grade Level....... 62

16. Comparison of CRT Scores by Schedule Type for Seventh Grade .................. 63

17. Independent $t$ Tests Comparing Percentages for Seventh Grade for All Schedule Types .................................................................................... 65

18. Comparison of CRT Scores by Schedule Type for Eighth Grade ................... 66 
19. Independent $t$ Tests Comparing Percentages for Eighth Grade for All Schedule Types....

20. Comparison of CRT Scores by Schedule Type for Ninth Grade

21. Independent $t$ Tests Comparing Percentages for Ninth Grade for All Schedule Types

22. Comparison of CRT Scores by Schedule Type for $10^{\text {th }}$ Grade

23. Independent $t$ Tests Comparing Percentages for $10^{\text {th }}$ Grade for All Schedule Types ....

24. Comparison of CRT Scores by Schedule Type for $11^{\text {th }}$ Grade.

25. Independent $t$ Tests Comparing Percentages for11th Grade for All Schedule Types.

26. Comparison of CRT Scores by Schedule Type for $12^{\text {th }}$ Grade.

27. Independent $t$ Tests Comparing Percentages for12th Grade for All Schedule Types.

28. Summary of Independent Samples $t$ Tests of CRT Scores when Disaggregated by Schedule Type and Grade Level 


\section{CHAPTER I}

\section{INTRODUCTION}

\section{Background of the Problem}

What constitutes the optimum circumstance for student learning is imprecise because of the effects of overlapping factors. For a high school student, learning is impacted by several variables, including: quality of the instruction, interest in the subject, family economic status, levels of previous success, distractions from home, distractions from peers, changing hormones, and time spent on task. Some of these factors are static and some are flexible. The amount of time spent in teaching and learning a particular curricular area is adjustable and the individual school has options as to how that time is allocated. A powerful influence on the parameter of instructional delivery is the schedule type of classrooms and schools. The constraints of schedule type can influence teacher pedagogy and student assimilation of knowledge.

In the secondary classroom, mathematics is universally part of the curriculum. Schools operate on a general agreement that all students in the United States should learn algebra by the end of high school (Bass, 2005). Starting with the acceptance of the Carnegie Unit of 1906, high schools have measured credits by the number of hours successfully spent in individual classrooms (Rosario, 2000). Following A Nation at Risk (National Commission on Excellence in Education, 1983) and the National Education Commission on Time and Learning (1994), considerations were given to alternative ways to manage the school year and the school day. One of the common changes to the school 
day was the shift to one of the forms of the block schedule; by 1995 more than half of all high schools were using the block schedule (Veal \& Flinders, 2001) and by 2008 over $72 \%$ of secondary schools used some form of the block schedule (Queen, 2009). The effect of these schedule changes school wide was not readily clear. Mathematics is universally taught but the influence of schedule changes on teacher pedagogy and teacher learning in the mathematics classroom was initially uncertain.

\section{Statement of the Problem}

Algebra has been a cornerstone of the mathematics and school-wide curriculum for centuries. While the presence of algebra in the school curriculum has not changed, the research methods and theoretical frameworks to determine if and how students learn algebra have changed often in the past hundred years. The concept of algebra being purely theoretical has evolved into an understanding of algebra as an accessible language which describes the world in both complex and simple ways. Algebra in the secondary school is the fundamental course for students' access to higher level mathematics and for access to our increasingly technological society (Haas, 2005). NCTM advocates the instruction of the basics of algebra to early elementary age students as well as advising and guiding educators in the methods to portray algebra as a dynamic and necessary vehicle in all students’ education (Burke, Erickson, Lott, \& Obert, 2001).

The manner in which the algebra class has been structured has changed in a significant way in the past 15 years. The more traditional classroom schedule has been largely replaced by the block schedule. Three of the reasons presented for a change in the 
mathematics classroom from the traditional 45-minute schedule to a block schedule included: more time in class for students to explore concepts, more time for the teacher to interact with the students, and more opportunities for the teacher to present in-depth and varied instruction (Gullatt, 2006). The three goals are generally achieved but the issue of how this change in scheduling influences students' learning of algebra remains.

In Utah, prior to the No Child Left Behind Act (NCLB), a state algebra test was administered to students in each district. When NCLB was implemented, Utah used that existing algebra criterion-referenced test (CRT) as a marker of student understanding and achievement. Actions were taken at the state level to assist districts and mathematics teachers to meet the challenge of NCLB standards. However, some of the schools were using the traditional schedule and some were using the block schedule. It was not known whether or not the schedule type and the associated instruction influenced algebra students' learning using the traditional schedule compared with algebra students using a block schedule. It is also important to understand whether or not the grade level of students has an impact on the CRT results when comparing schedule types. Many factors exist that influence student learning and one of the factors that can be changed is the schedule type in the algebra classroom.

\section{Significance of the Problem}

Because schedule types are a malleable factor in schools, knowing the influence of the instructional schedule type on algebra CRT scores may be significant in decision making for school administrators. After the implementation of NCLB, states and local 
school districts have been pressed to determine if adequate yearly progress (AYP) has occurred. Because of the universality of algebra for nearly all students, algebra has become one of the measures of AYP. State offices of education and school districts, which use state-sponsored standardized testing programs, have fostered a results-oriented instructional climate for individual schools and for individual teachers (Haas, 2005). States and districts are faced with the challenge to determine which teaching methods, school schedules, teacher training programs, textbooks and other educational dynamic have a positive impact on student learning in the algebra classroom.

The Utah State Office of Education (USOE) required a student to successfully complete three mathematics courses for high school graduation: algebra, geometry, and a third course from the approved list of mathematics courses (USOE, 2010). The requirement that all students must pass algebra in order to graduate from high school in Utah makes algebra of vital import. Until recently, Utah required that all high school students pass the Utah Basic Skills Competency Test (UBSCT); 60\% of the questions in the mathematics portion of the UBSCT test were pre-algebra and algebra questions (USOE, 2008). Even though it is not required in 2012, the UBSCT may again become part of a high stakes testing program in Utah. Regardless of the implications of testing, the “ideas of algebra are an indispensable component of mathematical literacy in contemporary life” (Burke et al., 2001, p. 5) and a determination of which classroom schedule is most effective should be pursued.

The algebra common core curriculum in Utah is published and available to all mathematics teachers. During the past 8 years, the topics of mathematics instruction, 
textbook use, considerations of the previous years’ disaggregated CRT scores, and teacher training focused on the specifics of student learning in the mathematics classroom. A piece that is lacking for mathematics is the clear understanding and use of research in decision making on the local and state levels; a targeted focus "on better linking research and practice is necessary to improve the landscape of educational research, the ways that it used in day-to-day decision-making in schools and districts, and, ultimately to improve student learning” (Arbaugh et al., 2009, p. 3). Schools and districts have the power to change school schedules and the evidence from research may be used to make school decisions. The algebra course is universal in secondary schools and a positive measure of students' scores in algebra indicates compliance to NCLB standards. A study that explores classroom schedule type and uses a common metric, Algebra I CRT scores, can be helpful in understanding the relationship between these two commonplace classroom components.

\section{Definition of Terms}

Each field of study has its own particular lexicon. Mathematics has very precise definitions for terms and concepts but the teaching of mathematics incorporates meanings that are specialized and contextual. Germane to understanding the review of literature and my research process is the meanings and common use of various classroom schedules and courses in Utah.

1. Traditional schedule: A schedule when each class period is approximately 50 minutes long and the class meets every day during the 180 day school year. This term 
does not imply the content of the curriculum nor the method of delivery is from a particular era; it is a reference to length of the class period.

2. Block A/B schedule: A schedule when each class period is approximately 88 minutes long and the class meets every other day during the 180 day school year; a total of 90 class meetings per year.

3. Block $4 \times 4$ schedule: A schedule when each class period is approximately 88 minutes long and the class meets every day for one semester; a total of 90 class meetings per year, all in the same semester.

4. Block schedule: A general reference to either the block $4 \times 4$ schedule or the block A/B schedule.

5. Modular schedule: Another name for the general term block schedule.

6. Trimester schedule: A schedule when the 180 day school year is divided into three 60 day semesters. Each class meets for approximately 60 minutes every day and students stay in the same class for two of the three trimesters.

7. Algebra: The mathematics course typically taken by students between $7^{\text {th }}$ and $12^{\text {th }}$ grades; more precisely named Algebra I.

8. Algebra II: The mathematics course which follows, and is a continuation of, algebra and will be referred to in this study only as Algebra II.

\section{Purpose of the Study}

This study will investigate the relationships between various mathematics classroom schedule types and results on Utah's criterion-referenced test for algebra 
students. A primary focus of this study is on the schedule type and its relationship to algebra CRT outcomes; a secondary focus is on the relationship between grade level and algebra CRT outcomes. The study will analyze all students on the traditional schedule compared to all those on the $4 \times 4$ block or A/B block. Algebra classes will be separated by grade level, for example, eighth-grade students on the traditional schedule compared to eighth-grade students on $4 \times 4$ block schedule.

Numerous studies describe secondary school schedules and achievement (Bass, 2005; Canady \& Hothkiss, 1985; Gruber \& Onwuegbuzie, 2001; Zepeda \& Mayers, 2006). However, few of these studies compare schedule type with state tests and none of these studies explore schedules and achievement in Utah. The importance of algebra as a mathematics cornerstone and the position of algebra in the analysis of adequate yearly progress, as deemed by NCLB standards, necessitate an examination of the conditions under which students learn algebra. Many of the factors which may impact student learning, such as, age, gender, SES, general aptitude, previous experiences in a math class, cannot be changed. These factors, along with teacher practice, teacher training, curriculum selection, instructional materials, and schedule type, all have potential impacts on student learning. However, for this study, schedule type will be the only one of these factors examined. By studying a large group of students in Utah and isolating one variable a starting point may be determined in terms of possible factors influencing student CRT scores. The schedule type used for the delivery of instruction can be reconsidered if it is determined that one particular schedule is significantly superior in terms of a measure of CRT scores compared to another schedule type. If the research 
findings in this study suggest that seventh, eighth, and ninth graders score significantly higher on Utah's CRT while being taught on the block schedule than those seventh, eighth, and ninth graders being taught on the traditional schedule then subsequent investigations can examine what factors (e.g., changes in teachers’ instruction, time allotted for learning activities) are a potential explanation for this finding. This study will examine the algebra CRT scores for over 30,000 Utah students who took the identical test, all during the same 6-week period. Such a large data set will shed light on potential relationships between schedule type and CRT scores.

\section{Research Questions}

The following research questions guided this study.

1. What is the relationship between mathematics instructional schedule type and student scores on Utah’s CRT for algebra, for all students?

2. What is the relationship between mathematics instructional schedule type and student scores on Utah’s CRT for algebra, by individual grade levels?

\section{Assumptions, Delimitations, and Limitations}

It was assumed that the information provided by the data miner in the USOE was accurate. It was assumed that the information gathered from the 41 separate school districts in regard to schedule types in use in each of their secondary schools was accurate. It was assumed that other factors that influence student scores existed but they were not a part of this particular study. I managed the collection of the data for district 
schedule type because the state did not have a record of the schedules for each separate school and care was needed to make sure that the type of schedule used within the schools was during the same time frame that the CRT data were created.

Delimitations are characteristics that have been consciously included or excluded from the study and affected the choice of my problem, the purpose of my study, and my research questions. For this study I selected data from students in Utah public schools. The dependent variable was scores on the state CRT and not measurements of chapter tests, grades, graduation rates, honor roll attainment, or any other measure of achievement. My using a singular CRT score does not indicate that that one score is the only, or all inclusive, measure of achievement. Indicators of student learning are complex (Schoenfeld, 2002) but this study focused on the one measure because it was universal to so many students in Utah and had important weight in the NCLB and state measure of student success. I studied the CRT scores for algebra, which is the ubiquitous course for secondary mathematics students. The choice to select schedule type as the independent variable aided in the simplicity of analysis and potential validity of the study. I did not choose to study how teachers alter their instructional delivery when they teach in each type of schedule parameter. I did not choose student socioeconomic status (SES), gender, race, or school size for this study; those factors did not have the same potential for alteration as the schedule of a school.

The limitations of a study are the parameters of the generalizations of the results of the study. For this study the topic is mathematics; therefore, an assumption could not be made that any results would apply to other secondary subjects. Utah has a 
demographically homogenous population in comparison to other states. The data for this study were taken from just one school year (2010-2011); it should not be assumed that the identical results could be obtained for any other school year. This was only a snapshot of groups of students and grade-level grouping for one school year; different groups of students and grade levels may have different variance in different years. If the results indicate that students on a particular schedule type score higher on the algebra CRT, there cannot be an assumption that other measures (student efficacy, GPA, SAT score) would also increase in the mathematics class with the same schedule. There could be multiple variables that were included in this study (teacher training, teacher instructional adjustment to different schedule types, student adjustment to new schedule type, textbook non-alignment to specific schedule type) that impact CRT performance other than schedule, but this study focused on the relationship between schedule type and CRT scores. 


\section{CHAPTER II \\ REVIEW OF LITERATURE}

\section{Scheduling Variations in the Algebra I Classroom}

The purpose of this chapter is to review the literature in regard to varying schedule types in the classroom and the ways these different schedules influence the classroom environment, teaching practice and, perhaps, student learning. A primary focus will be on these educational manifestations in the mathematics classroom. In the ongoing effort to maximize student learning, educators have explored and altered the structures of the educational system. Different grade levels, SES, subject areas, gender, and student abilities have prompted careful consideration of the impacts of school settings and instructional methods. This review of the literature provides the historical context for scheduling, different schedules that schools have used, the influences of schedule differences on teacher practice, and the influences of schedule and practice on student learning. The review compares students’ mathematics learning in different school schedule types, the research related to teacher practice in the mathematics classroom, considers the singular importance of algebra in the mathematics curriculum, and describes the various measures by which algebra teaching and achievement is evaluated.

\section{Historical Context}

Public schooling became widespread during the common school movement era of the early $19^{\text {th }}$ century with the growing belief that schools were for all children and that using a regimented system would dissipate learning (Kliebard, 2004). The social 
efficiency model of education, later in the $19^{\text {th }}$ century, viewed students as part of system in which efficiency was the overriding principle with little concern for individualization or the effectiveness of instruction. The lack of individualization and allegiance to the social efficiency model was questioned by John Dewey, Lucy Mitchell, Edward Thorndike, and others in the $20^{\text {th }}$ century. Their belief was that students were individuals and not just parts of a whole. The landmark report, A Nation at Risk (National Commission on Excellence in Education, 1983), questioned how educational time was being spent on instruction in the American public schools. In addition to A Nation at Risk, other "reports dating from the late 1980s and early 1990s focused on time-on-task with school schedules, [describing how] schools and communities have experimented with a variety of alternative schedules” (Gullatt, 2006, p. 250). The National Education Commission on Time and Learning (1994) expressly sought to discuss and discern the uses of time in regard to both the students' school schedule and in daily activities. The Commission on Time considered, for both elementary and secondary education, the parameters of traditional schedules, flexible schedules, extended days, year-round school, and other non-traditional schedules in the contexts of the United States and in international educational settings. Students' use of time was examined both in the school and at home, including such activities as extracurricular sports and television viewing time. The report surveyed the types and amounts of time that students used in various activities but did not express a conclusion as to what was the most effective classroom schedule to increase student progress (Copple, Kane, Levin, \& Cohen, 1992). This influential commission spurred debate and left open opportunities for researchers to 
conduct studies to attempt to determine the most effective school schedule (Geerstle \& French, 1993; Lakoff \& Nunez, 2000). The impetus for these reports and reviews on how student spent their learning time was an underlying belief that scientific study, not previous common practice, would yield the most effective framework for use of classroom time and for the optimization of educational practice.

\section{Common $6^{\text {th }}$ - Through $12^{\text {th }}-$ Grade Schedule Types}

Today, four schedule types are common in U.S. schools. These schedule types are presented in Table 1. A traditional schedule consists of a school year of about 180 days and a daily schedule consisting of six or seven separate class periods; these class periods are generally 50-55 minutes in length. This schedule does not imply the type of instruction nor the content but the organization of time in the classroom. In a $4 \times 4$ block schedule students have four classes per day and have the same four classes each day for one 90-day semester and switch to four different classes for the next 90-day semester. Each of these class periods is about 88 minutes long. A block $A / B$ schedule means the class periods are approximately 88 minutes long and students have four classes one day and four different classes the next day, thus the A-day and a B-day designation. The block A/B schedule is the same for a student for the entire school year unless they have a $1 / 2$ credit class, which will last 88 minutes per day for one semester. Mathematics block courses are generally 88 minutes per day for 90 school days per year. In addition, in the trimester schedule generally has the 180 day school year is divided into three parts and students take a mathematics course for two (or three) of the three trimesters for about 70 minutes per class period. 
Table 1

Schedule Types Comparison

\begin{tabular}{llcc}
\hline Schedule type & \multicolumn{1}{c}{ Meeting days } & $\begin{array}{c}\text { Approximate minutes } \\
\text { per class period }\end{array}$ & $\begin{array}{c}\text { Approximate hours in } \\
\text { math class per year }\end{array}$ \\
\hline Traditional & $\begin{array}{l}\text { Math every day (180 math } \\
\text { days) }\end{array}$ & 50 minutes & 150 \\
4x4 block & $\begin{array}{l}\text { Math every day; one } \\
\text { semester (90 math days) }\end{array}$ & 88 minutes & 132 \\
A/B block & $\begin{array}{l}\text { Math every other day; full } \\
\text { year (90 math days) }\end{array}$ & 88 minutes & 132 \\
Trimester 2/3 & $\begin{array}{l}\text { Math every day for 2 } \\
\text { trimesters, 120 days per } \\
\text { year }\end{array}$ & 70 minutes & \\
Trimester 3/3 & $\begin{array}{l}\text { Math every day for all three } \\
\text { trimesters }\end{array}$ & 70 minutes & 210 \\
\hline
\end{tabular}

Throughout the many school districts in the United States other less common types of schedules exist. The research studies described below focus primarily on the traditional, the 4 x 4 block, the block A/B, and the trimester schedules, which are the most frequently used schedule types in Utah (USOE, 2011a).

\section{Rationale for Various Classroom Schedules}

Educational reformers have been grappling with how educators can better use the school day to improve student learning (Gullatt, 2006; Sizer, 1992). In the 1990s, educators considered how students learn and what structures facilitate learning. One consideration was the daily classroom schedule in the secondary schools, which had been virtually unchanged for 200 years. Many of the factors that students bring to the 
classroom cannot be changed, which has led schools to consider changing factors over which schools do have control. A shift in the perception of the usefulness of the traditional school model transformed educational thought: "Decades of school improvement efforts have floundered on a fundamental design flaw, the assumption that learning can be doled out by the clock and defined by the calendar” (Copple et al., 1992, p. 13). Because the traditional schedule was already in place, no one provided a rationale for it. Forman (2009) described how learning has been discussed in terms of length of the school year, length of the school day, and the structure of the school day. Based on various theories, schools experimented with different schedule types. During the last fifteen years, research has examined the success, or lack of success, of those scheduling changes. Many school districts shifted to using a block schedule, either A/B or 4 x 4, for similar reasons.

The most common reason cited for using a block schedule is a longer period of instruction, whereby teachers can delve more deeply into the content of a lesson and provide students with more authentic learning opportunities, such as a laboratory experiences, cooperative group work, and project-based learning tasks. (Biesinger, Crippen, \& Muis, 2008, p. 191)

Therefore, if the block schedule is used by teachers to enable more time for the in-depth study of mathematical content then this shift in instructional practice has the potential to influence learning and achievement. Biesinger and colleagues (2008) wrote about the mathematics classroom and the need for math students to have non-lecture time to gain a greater understanding of complex ideas. In terms of subject areas, "mathematics is presently the most discussed core subject area when the concept of block scheduling is approached” (Gullatt, 2006, p. 256). Proponents of the block schedule contended that 
more time in the classroom, with less teacher lecturing, allows for additional instructional approaches (Canady \& Hothkiss, 1985; Jenkins, Queen, \& Algozzine, 2002). Canady and Hotchkiss provided a significant and early study of the newly emerging block scheduling movement. They found that the teachers had more time for planning, interacted with fewer students each day, and that limited gains were achieved in both reading and mathematics. In addition, they concluded that these early years of block implementation lacked consistent administrative support and teacher training. Besides moving away from lecture-based classrooms, schools began to move toward standards based education. Flynn, Lawrenz, and Schultz (2005) described the convergence of the efforts to reduce traditional delivery methods with a new push toward block scheduling and the emergence of national standards in mathematics. They reported that the shift to block scheduling had potential for an alteration of classroom practice but their study concluded that "simply changing the structure of the school schedule cannot act as the sole catalyst for instructional change. Teachers in the block-schedule settings may need to be provided with ongoing professional development to optimize the benefits of the extended period schedule” (Flynn et al., 2005, p. 18).

Additional rationales for schedule changes included the opportunity for teachers to re-evaluate their pedagogy, the additional number of courses a secondary student could take per year, less time spent on roll call and other paper work, and the reduced time students spent passing in the hallways because of fewer class changes per day (Deuel, 1999; Lewis, Dugan, Winokur, \& Cobb, 2005). Educators viewed these organizational structural changes as additional benefits along with the perceived academic advantages 
afforded to students through the shift to block schedules in many schools. However, some educators questioned the touted advantages of the new schedules. In the aptly titled Block Scheduling and Advanced Placement Mathematics: When Tradition and Reform Collide, Howard (1997) reported that mathematics and science teachers complained that they were forced to reduce the number of concepts covered in class because the longer class periods did not compensate for fewer days in class. In particular, the timing of an A.P. course that ends in December with the A.P. test itself, which occurs in May, was seen as problematic. Other concerns emerged with the trimester and block schedule including increases in class size, the difficulties of daily pacing, the reduction of total hours for a course in the entire school year, and concerns about students' ability to stay on task for 90 minutes. Studies focused on whether or not block or trimester schedules improved the learning atmosphere in the classroom and the school, favorably altered teaching methods, or most importantly, could be connected to student learning (Arnold, 2002; Canady \& Rettig, 1993; Flynn et al., 2005). This literature review will not attempt to describe the broad range of this research but will instead focus more specifically on the relationship between mathematics classroom schedules and algebra. Mathematics classes have been taught with the traditional school schedule for many years and algebra has been a part of the mathematics curriculum for hundreds of years.

\section{Role of Algebra in the School Curriculum}

Formal education has included mathematics as part of the curriculum ever since schools were organized. In the curriculum, the practical uses of arithmetic and geometry 
have been counterbalanced with the purely theoretical study of mathematical thought. Algebra, the symbolic system of equations, polynomials, exponents and functions, was introduced to Western nations in the early $13^{\text {th }}$ century by Fibonacci after his travels through middle-Eastern Arabic regions. Today, schools operate on a general agreement that all students in the United States should learn algebra by the end of high school (Bass, 2005). The distinctions between arithmetic and algebra are not always agreed upon. Practitioners may find differences in approaches to instruction and use of symbols, but mathematics researchers identify many aspects of algebra in the typical arithmetic curriculum (Carraher \& Schliemann, 2007). In the traditional school schedule, algebra is taught every day for the entire secondary school year.

While the presence of algebra in the school curriculum has not changed, the research methods and theoretical frameworks to determine if and how students learn have changed often in the past hundred years. When examining student learning of algebra, the Piagetian lens of cognitive development prevailed in the 1960s and 1970s, which was followed by a focus on skills-based behaviorism (Kieran, 2007). An awareness of the universality of algebra in the United States caused an upsurge in the research on the teaching of algebra in the context of the socio-cultural framework; if Algebra for All, as promoted by NCTM (National Council of Teachers of Mathematics, 2008), was to be taken seriously, then the methods of instruction and the means of learning algebra needed to be examined in the context of the setting of particular schools. Increased research focus on algebra prompted researchers to examine the schedule under which students learn algebra because it is one of the contextual factors. Typically schools operate within 
either a block schedule or a traditional schedule.

\section{Research on Classroom Schedules, Mathematics, and Algebra I}

Educational studies measure a wide variety of factors, and the studies measuring success or nonsuccess of different scheduling models in the mathematics classroom are no exception. A shift in schools' schedule type led to a change in teacher attitude and practice which, in turn, frequently led to a change in student achievement. Studies of different schedules have focused on teacher satisfaction (Howard, 1997), the amount of time teachers used different strategies (Deuel, 1999), changes of self-efficacy of students (Biesinger et al., 2008), changes of GPA in the school (Trenta \& Newman, 2002), and changes of student test scores (Ellis, 2004; Hancock, Mattox, \& Queen, 2005; Lewis et al., 2005). The findings of these studies are discussed in the sections that follow. This body of research does not have a common metric so close examination is required to discern what is being measured and how it is measured to help determine what type and degree of success, if any, has been achieved.

\section{Teacher Attitudes and Practice}

When changing schedules, teacher training can have a positive impact on teacher efficacy and student behavior and learning within the school (Veal \& Flinders, 2001). When teachers' attitudes and practices are studied in regard to schedule type, the results are another data point to consider. Veal and Flinders investigated the impact of a 4 x 4 block schedule on one group of teachers compared with another group of teachers who remained with the traditional schedule, and a third group who taught on a hybrid of the 
two. In a large midwestern high school four measures of change were monitored and studied: methods of teaching, opportunities for teacher reflection, student-teacher rapport, and levels of teacher anxiety. The teachers had not been randomly assigned to each schedule type; assignment was voluntary $(N=77)$. The data were collected with a Likert scale questionnaire administered twice during the school year. In terms of methods of teaching, $45 \%$ from the block schedule and $42 \%$ from the hybrid groups agreed that they had made significant changes in their teaching methods for that one school year compared with $24 \%$ of the teachers teaching on the traditional schedule. This demonstrates the influence that schedule type can have on instructional methods. All three teacher groups were split (improved, reduced, stayed the same) concerning any differences in student-teacher rapport. As might be expected, the teachers with the hybrid and block schedules reported more anxiety than those on the traditional schedule because significant educational setting changes tend to create anxiety about new expectations and activities (Veal \& Flinders, 2001). While reviewing similar studies, Gullatt (2006) noted nearly equal numbers of positive results and negative results: with the successes generally related to the opportunities for teachers to implement a variety of classroom methods, opportunities for students to take more elective courses, and the opportunity for students to repeat failed classes without attending after school or summer school programs and the negatives included inadequate preparation for advanced placement examinations ( $4 \mathrm{x} 4$ block), difficulties of students to retain mathematical knowledge for seven months ( $4 \times 4$ block), and inadequate teacher preparation in time management leading to teachers’ difficulty in "covering” all required mathematical topics. 
Researchers in North Carolina examined teacher attitudes and practices under various schedule conditions and with all secondary subject matters (Jenkins et al., 2002). A sample of 2,167 teachers answered questionnaires about various instructional practices and how those practices related to the type of schedule that was used in their particular school. The authors concluded, "Our findings suggest that these approaches are not embraced differently for teachers in schools with block or traditional scheduling models" (Jenkins et al., 2002, p. 201), and they questioned the use of different schedules if the teaching preparation and practice did not differ. This demonstrates that the schedule may not influence instruction.

As school districts consider various methods to improve schools and student performance, they can base their deliberations upon a growing body of evidence. A study in Florida compared the impact of the $4 \times 4$ block schedule and the traditional schedule on academic achievement, student behavior, and staff perceptions of more than 50,000 secondary students in all subject matters (Deuel, 1999). The study took measurements after the second year of the block schedule's implementation so that benefits would tend to be established and not reflect transitory effects limited to the first year of implementation. Among the findings was that $75 \%$ of the teachers indicated the longer block periods increased individualized attention for students and 84\% of the block teachers were able to experiment with new teaching methods, which demonstrates the influence of implementation of the block schedule on teacher practice.

\section{Student Behaviors}

A change in school schedule types, either from traditional to block or from block 
to traditional, generates an impact on students. The students, along with the teachers, are required to adjust to different classroom time lengths, homework assignment time lengths, and a shift in teaching methods. Flynn and colleagues (2005) investigated differences in eighth-grade mathematics students’ engagement in standards-based curriculum and instruction practices between block and traditional schedule schools. The study examined the characteristics and classroom practices of 62 middle-level schools in three states: Louisiana, Illinois, and Colorado. Seventeen different classroom activities were measured, primarily, by completion of a survey by the classroom teachers. Among the measured items were percent of time working on "real world problems," participation in student-led discussions, and formal student presentations in class; all these activities had been touted as advantages of a block schedule compared to the traditional schedule. However, Flynn and colleagues (2005) concluded:

The results also support [other] research showing that, although teachers in blockschedule schools are provided with more time per class period for instruction, it does not appear that they are using that time to vary instructional practices compared to traditional-schedule teachers. Simply changing the structure of the school schedule cannot act as a catalyst for instructional change. (p.15)

This demonstrates that anticipated changes in students' mathematics activities did not occur because of the influence of a change to the block schedule. In contrast, Biesinger and colleagues (2008) used a mixed method quasiexperimental design to understand the impact of an alternative block schedule on students' self-efficacy, attitude, and classroom practice in mathematics. To gauge changes in attitude, the 242 participants in the study from four different high schools, including the control group, responded to the FennemaSherman Attitude Scale before and after switching from a traditional schedule to a block 
A/B schedule in comparison with a group of students whose school had remained in the traditional schedule. A statistical analysis suggested that the implementation of the block A/B schedule resulted in significant changes $(p<.012)$ in student positive attitudes toward themselves and mathematics, although the effect size was small (Biesinger et al., 2008). The authors did acknowledge that further study after more time had elapsed would be needed. A Florida study (Deuel, 1999) of 50,000 students in 24 secondary schools compared three types of problematic student behavior: mean daily attendance, internal suspension rate, and external suspension rate. Results showed no difference between the block students and the traditional students; this demonstrates that some suspected benefits of transition to the block schedule were not evident in the Deuel study.

\section{Student Achievement}

Many states and school districts have switched from the more traditional schedule to the block schedule and researchers have measured the results of these changes in terms of student achievement. Studies have used an array of measures to compare traditional school schedules and block or hybrid schedules but the main question should be: did the students learn more? That question depends upon what is being measured as learning. A meta-analysis of studies devoted to impacts of block schedules on classroom practices and student learning conducted by Zepeda and Mayers (2006) reported very mixed results; when comparing twelve studies that had reputed to measure the influences of block or traditional schedules on student success, the results were somewhat inconsistent. From the analysis of several studies, three studies (Arnold, 2002; Cobb, Abate, \& Baker, 1999; Wronkovich, Hess, \& Robinson, 1997) reported lower mathematics achievement 
for block students compared to traditional students, two studies (Gruber \& Onwuegbuzie, 2001; Lawrence \& McPherson, 2000) reported block-scheduled students outperformed traditional-scheduled students in four core academic areas and Spencer and Lowe (1994) reported traditional scheduled students scored higher in English.

Table 2 organizes some of the studies discussed in the literature review and indicates mixed results in student achievement, student self-efficacy, and teacher practice in terms of a more valuable schedule type.

Table 2

Summary of Research of Differences by Schedule Type

\begin{tabular}{|c|c|c|c|}
\hline Author(s) & Subject/measure & Difference & Block or traditional \\
\hline $\begin{array}{l}\text { Lawrence \& McPherson } \\
\text { (2000) }\end{array}$ & $\begin{array}{l}\text { N. Carolina State test } \\
\text { Algebra } 1\end{array}$ & $\begin{array}{l}M=54.20 \text { trad } \\
M=48.22 \text { block }\end{array}$ & $\begin{array}{l}\text { Trad. students } \\
\text { scored higher }\end{array}$ \\
\hline Lewis et al. (2005) & $\begin{array}{l}\text { Colorado students } \\
\text { ACT test }\end{array}$ & $\begin{array}{l}\text { Block A/B = } 20.34 \\
\text { Block } 4 x 4=20.58 \\
\text { Trad. }=20.36\end{array}$ & $\begin{array}{l}\text { No significant } \\
\text { difference }\end{array}$ \\
\hline Trenta \& Newman (2002) & $\begin{array}{l}\text { Ohio Proficiency } \\
\text { Scores }\left(9^{\text {th }} \text { grade }\right)\end{array}$ & "Positive trend" & $\begin{array}{l}\text { Block students } \\
\text { higher }\end{array}$ \\
\hline Trenta \& Newman (2002) & Ohio ACT scores & "Positive trend" & $\begin{array}{l}\text { Block students } \\
\text { higher }\end{array}$ \\
\hline Ellis (2004) & $\begin{array}{l}\text { N. Carolina biology } \\
\text { end-of-level; }\end{array}$ & Biology = "no difference" & No difference \\
\hline Ellis (2004) & $\begin{array}{l}\text { Algebra } 1 \text { end-of- } \\
\text { level; } 4 \text { N. Carolina } \\
\text { schools }\end{array}$ & $\begin{array}{l}\text { Algebra } 1 \text { = "sign. } \\
\text { difference } 4 \times 4 \text { block vs. } \\
\text { trad. }\end{array}$ & $\begin{array}{l}\text { Block students } \\
\text { higher }\end{array}$ \\
\hline $\begin{array}{l}\text { Zepeda \& Mayers meta- } \\
\text { analysis: Arnold, (2002); } \\
\text { Cobb et al. (1999); } \\
\text { Wronkovich et al. (1997) }\end{array}$ & $\begin{array}{l}\text { Several mathematics } \\
\text { measures }\end{array}$ & & $\begin{array}{l}\text { Trad. Students } \\
\text { scored higher }\end{array}$ \\
\hline Jenkins et al. (2002) & $\begin{array}{l}\text { Teacher practice } \\
\text { changes with } \\
\text { schedule shifts }\end{array}$ & $\begin{array}{l}\text { "No differences” between } \\
\text { block and trad. schedule } \\
\text { teachers practice }\end{array}$ & No difference \\
\hline Biesinger et al. (2008) & $\begin{array}{l}\text { Algebra students' } \\
\text { overall self-efficacy }\end{array}$ & $\begin{array}{l}M=2.32 \text { trad. } \\
M=5.45 \text { A/B block }\end{array}$ & $\begin{array}{l}\text { Block students } \\
\text { scored higher }\end{array}$ \\
\hline
\end{tabular}


Lawrence and McPherson (2000) defined learning as a score on North Carolina state tests. The results surprised the authors; students scored higher on the Algebra I state test with the traditional schedule $(M=54.20)$ compared to the block schedule $(M=$ 48.22). In addition, students scored higher on the traditional schedule on three other state tests: biology, English 1, and U.S. history. These results demonstrate that the introduction of the block and hybrid schedules did not have a positive influence on state test scores. Trenta and Newman (2002) analyzed the data from a study that compared block or traditional schedules in relation to the Ohio proficiency tests for ninth graders, ACT scores and attendance. They concluded that a positive trend was evident in the academic areas for all four subject matters of the proficiency test and there was "reason to say there is support for the inference of 'an influence' on academic success” (Trenta \& Newman, 2002, p. 58) after the introduction of the block schedule in the studied schools.

One way researchers have measured academic achievement is by comparing results on standardized tests. In a comparison of ACT mathematics scores in three Colorado high schools with three different schedule types, the students whose school had a traditional schedule $(N=1,684)$ had a mean ACT score of 20.36, the students whose school had a block A/B schedule $(N=1,669)$ had a mean score of 20.34; and the students whose school had a 4 x 4 block schedule $(N=1,821)$ had a mean score of 20.58 (Lewis et al., 2005). These scores indicate that the differences were small for the ACT scores, only those students on a $4 \times 4$ block mathematics schedule having a positive effect size of $d=$ 0.19 (Lewis et al., 2005). Using a different assessment tool, Massachusetts administers mandated State assessment in mathematics and language arts, the Massachusetts 
Comprehensive Assessment System (MCAS). Forman (2009) reported the results from the same high school when it was using the traditional schedule and then three years after that high school had changed to a 4 x 4 block schedule. The mathematics pass rate was $64.0 \%$ for those students $(n=146)$ on the traditional schedule and $85.6 \%(n=236)$ for those who were on the block schedule. The rather large increase in the percentage of students who passed the MCAS mathematics test, a $21.6 \%$ increase; three questions arose while examining the study and its data: why did the passing rate have a mean value listed (should it not have just been a percent who pass?), why did that listed mean of $64.4 \%$ have a standard deviation of 0 , and why did the $n$ increase so much in the same school in 2 years? These concerns with methodology and data analysis cast doubt on these findings, especially when viewed in light of the other studies reviewed here that show little or no impact on achievement under different schedule conditions.

Additional scores on state benchmark mathematics tests have been compared under different school schedule conditions. A study in North Carolina compared test results for students in four different high schools in the Cumberland County School System (Ellis, 2004). End-of-course tests in Algebra I and biology were compared for students on the traditional schedule and students on the $4 \times 4$ block schedule. Results were disaggregated in terms of gender, minority or non-minority. At the end of 2 years, there was no statistical difference for the biology scores, but "there was a significant difference in student achievement for all students, minority, non-minority, female, and male in Algebra I on the 4 x 4 schedule versus all students, minority, non-minority, female, and male in Algebra I on the traditional schedule” (Ellis, 2004, p. 2), indicating 
that Algebra I students on the $4 \times 4$ block scheduled scored higher on the end-of-course test than those students on the traditional schedule.

\section{Summary}

Although an abundance of studies has examined student learning, student selfefficacy, teacher satisfaction, and student achievement, the dissimilar variables used in the methods and different perspectives to assess the results make a clear cut conclusion problematic. There remains a need to study student achievement when algebra is taught on different schedules, on a wide scale, with a common metric of achievement. The results have the potential to drive educational decisions about which schedule type is more effective. When a school changes from one schedule type to another, the first step to improved student learning is the ability and willingness of teachers to change their practice, followed by students' shift of behaviors in regard to the new schedule, with the desired final result being increased student achievement. A schedule change alone does not appear to create significant, positive results, "because there are so few differences between the block and traditional schedule” (Flynn et al., 2005, p. 21) without significant change in teacher pedagogy (Jenkins et al., 2002). The traditional class length schedule

and the various block schedules have their individual advantages. Teachers' abilities and efforts are the major force behind successful classrooms. When schedules change, it may allow teachers to expand the repertoire of methods they bring to their work (Veal \& Flinders, 2001). By only using the variable of schedule type difference in a study, other factors that may create success remain more statistically neutral. Current research has 
introduced compliance to NCLB requirements as a new factor within schools that could complicate the study of the effectiveness of the traditional and block schedules with the added pressure of adequate yearly progress. Replicating previous study results is difficult as implementation methods and teacher training appear to be focused on NCLB requirements and vary by school site (Biesinger et al., 2008).

Because researchers have used a wide ranges of measures, an analysis of the block schedule remains inconclusive (Zepeda \& Mayers, 2006). Many claims have been made about traditional, trimester, and block schedules and because many districts have adopted new schedules "it behooves practitioners and scholars to continue inquiry" (Zepeda \& Mayers, 2006, p. 160). Educational change for change itself is rarely successful. Previous studies of secondary school schedule types suggest varying rates of success in the algebra classroom by using a variety of measures. Installing a different schedule in a district or school may only result in a different bell schedule unless issues concerning teacher preparation are addressed and quality research is conducted. This proposed study will assess one measure of student learning using a valid and reliable measure, Utah’s algebra CRT scores, and examine its relationship to classroom schedule type. 


\section{CHAPTER III}

\section{METHODS}

\section{Overview of the Methods}

This chapter discusses the methods which were used to compare various school schedule types in relation to Utah's Algebra I CRT. Student achievement is derived from a myriad of factors; test scores are just one measure of student achievement. The different schedules in which a student is taught may influence the practice of the teacher within each schedule type. However, it is also true that teachers use many different instructional methods within a single schedule type. Students' ability to learn with different time constraints and to adjust to varied instruction may influence student learning. Changes in schedule types may impact teacher practice, student classroom learning behaviors, and various measures of student learning. This study examined differences in algebra CRT scores in relation to schedule type and grade level. An important factor was to isolate the type of schedule in which students were taught and compare these schedule types with Utah's algebra CRT scores. State and district administrators have decision making power in regard to selection and authorization of schedule types in public schools. This study provided data which suggested which schedule type, for different grade levels, yields higher scores on a NCLB required CRT. The research methods were quantitative and used statistical analysis of preexisting descriptive state-level data. For this study a multinomial logistic regression model was used to conduct the data analysis of Utah students’ Algebra I CRT scores as influenced by schedule type and grade level. 


\section{Research Questions}

The following research questions guided this study.

1. What is the relationship between mathematics instructional schedule type and student scores on Utah's CRT for algebra, for all students?

2. What is the relationship between mathematics instructional schedule type and student scores on Utah's CRT for algebra, by individual grade levels?

\section{Research Design}

The multinomial logistic regression design for this study allowed an analysis that was both powerful and multifaceted for a large data set. The research questions entailed using two categorical independent variables: schedule type, and grade level. The dependent variable was an ordinal and categorical measure of students' CRT scores. There were several possible design methods considered for the analysis of the study. A $t$ test is effective in comparing one set of means or percentages to another set of means or percentages when the variance of the populations are unknown. However, the dependent variable for the set of available data for the CRT scores was not continuous. The Utah CRT scores were reported as “ 1 (minimal), 2 (partial), 3 (sufficient), or 4 (substantial)” and were neither based on an interval scale nor continuous. An ANOVA design was also considered, but the lack of a continuous dependent variable prohibited the use of ANOVA, and ANOVA could not address the questions of this study. A linear mixed models design was considered, but rejected, because the linear mixed model requires the data to be normally distributed. The CRT scores $(1,2,3,4)$ did not have a normal 
distribution. Also, in a linear mixed model "the dependent variable is assumed to be a normally distributed quantitative variable which is linearly related to the fixed and random factors and covariates in the model. Do not use a multinomial variable [in a linear mixed model] as a dependent” (Garson, 2011, p. 19). Considering the issues with the dependent variable, the multinomial logistic regression model was selected because it was the best fit for the data in this study. Typical logistic regression is used on a dichotomous outcome, but this study’s dependent variable had four levels. Therefore, a specialized version of the logistic regression model, multinomial (also known as polychotomous or polyomous) logistic regression was selected as the most appropriate statistical method for this study. From the statistical results of the multinomial logistic regression further analyses was conducted using independent samples $t$ tests for percentages.

\section{Logistic Regression}

Logistic regression is used to measure the relationship between independent and dependent variables. Regression methods such as linear, logistic, and ordinal regression are useful tools to analyze the relationship between multiple explanatory variables and student results (Chen \& Hughes, 2004; Thomas \& Galamos, 2004). Logistic regression (also referred to as a logit model) can be used to predict a categorical dependent variable on the basis of continuous and/or categorical independents, to rank the relative importance of independents, and to assess interaction effects. Regression is commonly used to suggest factors in student learning. "Logistic and Cox regression methods are practical tools used to model relationships between certain student learning outcomes and 
their relevant explanatory variables” (Chen, 2005, p. 17). The impact of independent variables on the dependent variable(s) is usually explained in terms of odds ratios (Garson, 2011). Odds ratios are defined as the ratio of the predicted probability of an event to the predicted probability of not being the event (Cohen, Cohen, West, \& Aiken, 2003). For example, the ratio of the number of Utah families who have children living at home to the number of Utah families who do not have children living at home can be expressed as a ratio. The ratio is frequently put into a decimal form. Importantly, the dependent variable is non-continuous. If two dependent variable classes are present, the binary logistic regression model is used (e.g., teenager/not teenager). If more than two dependent variables classes are present then a multinomial logistic model should be employed.

\section{Multinomial Logistic Regression}

Multinomial logistic regression is used to handle the case of dependent variables with more than two levels. In this study there were two independent variables and each of these had individual categories. For example, grade level included all grades from seventh through twelfth, and schedule type had four types of schedules. In addition, binomial and multinomial logistic regression supports only a single dependent variable. For multinomial logistic regression, there may be two or more categories but the dependent variable is never a continuous variable (Chen \& Hughes, 2004). The dependent variable in this study (student CRT scores) were not continuous, had four categories and, therefore, warranted the use of the multinomial logistic regression design method. 


\section{Variables Used and Assumptions}

For this study the independent variables, schedule type and grade level, were categorical. Schedule type was separated into A/B block schedule, traditional schedule and two types of trimester schedules. Grade level included all grades from $7^{\text {th }}$ grade through $12^{\text {th }}$ grade. The dependent variable was CRT score on Utah's Algebra I test. This variable was ordered and categorical. The reported scores, based on USOE policy, were 1 (minimal), 2 (partial), 3 (sufficient), or 4 (substantial). In addition, the USOE directed this researcher to exclude any scores from the data that came from a school which reported 10 or fewer scores. The thought was that, in consideration to the Family Educational Rights and Privacy Act (FERPA), too few a number of scores from an individual school could possibly lead to identification of individual students.

My assumptions for the data were that more than one schedule type existed and that reported CRT algebra scores contained more than one hundred students for each grade level. Another assumption was that grade level for students who take the algebra CRT would not have equal sample sizes; this assumption was correct. Many more $7^{\text {th }}$ and $8^{\text {th }}$ graders took the CRT test than $11^{\text {th }}$ or $12^{\text {th }}$ graders. Another assumption was that proficiency scores on the CRT would not have equal sample sizes, and this assumption was also correct. After the data were collected the underlying assumptions were addressed through analysis of normalcy using the software called Statistical Package for the Social Sciences (SPSS; also referred to in the literature as PAWS 18 or SPSS-IBM). The assumed nonnormalcy of the data was correct, so multinomial logistic regression design was used for analysis of the data. 
For this study, the questions required the use of data from the USOE. The data were collected, organized, and transmitted in a specific manner by the USOE. After examining the data a multinomial logistic regression model was considered and used because of the questions asked and the data available.

\section{Participants and Setting}

The participants in this study were 46,291 public school students in Utah who had taken the Algebra I CRT. All students had taken the exact same Algebra I test during the same time frame--May $1^{\text {st }}$ through June $1^{\text {st }}, 2011$. The students came from almost every school district in Utah. Table 3 shows the distribution of Utah's schools and students by demographic categories.

\section{Table 3}

Utah Student Demographics

\begin{tabular}{lc}
\hline \multicolumn{1}{c}{ School categories } & \# of students \\
\hline Utah public schools & 899 \\
Number of students & 491,206 \\
Utah elementary schools & 501 \\
Utah middle schools & 142 \\
Utah high schools & 187 \\
Number of male students & 252,342 \\
Number of female students & 237,680 \\
Asian-Pacific Islander students & 14,256 \\
American Indian-Alaskan students & 7,569 \\
Black students & 5,457 \\
Hispanic students & 54,078 \\
White (non-Hispanic) students & 408,662 \\
\hline Source: Utah Public School Directory (USOE, 2011b).
\end{tabular}




\section{Students Excluded from This Study}

There were five groups of students who did not have their scores included in the data analysis for this study. The first exception was the 23 sixth-grade students in Utah who took the Algebra I CRT. This was deemed too small a sample for the grade level to be meaningful. The second type of exception were those students who were in the Youth in Custody program of Utah. Twenty-four school districts have Youth in Custody programs for those youth who have been arrested and are, or were, in the custody of the State. These schools have a different purpose and perspective than the other middle schools or high schools in their district and the students have too many extenuating circumstances which caused them to be excluded from the data set for this study. All students are different from one another in many ways, but the reasons for being in a Youth in Custody school, and the setting and operation of those schools, make their inclusion in this study unwarranted. The third exception for inclusion in the study were those students enrolled in an alternative high school. Alternative high schools are within the geographic boundaries of a school district but do not necessarily have the same guidelines, purpose, and mathematics programs. Students in alternative high schools are enrolled for a variety of reasons: habitual nonattendance at their regular high school, pregnancy, being a member of the Youth in Custody program, dropping out of traditional public school, having multiple failing grades in the regular high school, or having been in violation of the safe schools policy. There were approximately 324 students from alternative schools who took the Algebra I CRT that were not included in this study. Utah's alternative high schools provide a valuable service for their students and many 
notable successes have occurred for those students. Data from these schools' algebra CRT were excluded from this study because of the difference of these students' circumstances and educational history compared to the majority of the algebra students in the state.

The fourth exception was students in a Utah charter school. The charter schools are part of the public school system and are under the guidance of a state agency but do not belong to any particular school district. Each charter school has its own separate charter, or purpose, and the comparison to public schools in separate school districts, in this study, would have introduced another variable with unclear parameters. Charter schools have only recently had their Algebra I CRT scores placed into the USOE databank and their baseline scores are new. In addition, six of the charter schools operating in 2011 had 10 or fewer students take the CRT and their inclusion would violate the conditions of the use of the USOE data. The number of charter school students who were excluded was 3,258 for the two above-mentioned reasons. A study of the comparison of charter schools CRT scores to district CRT scores would be a useful study in the future. The fifth exception was the exclusion of students from schools whose number of students was deemed too small to be a relevant sample size or would violate the FERPA concerns of the USOE. The Tintic District, a very rural district, had a total of 17 students in all grades in the entire school district who took the CRT. The Rich School District, another rural district, had a total of 30 students take the CRT across five grade levels. For example, Harris Intermediate School in the Box Elder District had only one student take the CRT, and was, therefore, not included in the data set. 
In total, the removal of these five types of schools and grades accounted for less than 10 percent of the students who took the algebra CRT in Utah at the end of the 20102011 school year.

\section{Data Sources}

There were two primary sources of data used in this study: Algebra I proficiency scores and Algebra I classroom schedule types for most of Utah's secondary schools. The Algebra I proficiency scores used for this study came from the databank collected and stored by USOE at the end of the 2010-2011 school year. Some students took the test in their individual classrooms using the State's paper version of the test by marking an electronically scored sheet (Scantron) and other students took the test online. The test items for the paper-and-pencil test and for the online test were identical. Data were gathered with assistance and permission from the USOE data miner, Aaron Brough (see Appendix B). These data were not in the form of raw scores for each of the Utah students who took the CRT but were instead in the form of a proficiency score breakdown for all algebra students in each grade level in each school (see Appendix C). Table 4 shows the flow from a student's raw score on the Algebra I CRT to their reported proficiency score. A raw score for the CRT was the number of correct responses for the 70-item test. The proficiency score was a scaled score assigned by the USOE. The proficiency scores changed the raw score to an ordinal score from 1 to 4 . The data obtained for all Utah algebra students, with the method of display of the original data, were determined by USOE policy. 
Table 4

2010-2011 Algebra CRT Scoring Classifications

\begin{tabular}{llcl}
\hline $\begin{array}{l}\text { Raw score } \\
\text { (based on 70-question test) }\end{array}$ & Scale score & $\begin{array}{c}\text { Proficiency } \\
\text { score }\end{array}$ & $\begin{array}{c}\text { Proficiency score } \\
\text { name }\end{array}$ \\
\hline 0 -32 & $0-150$ & 1 & Minimal \\
$33-37$ & $151-159$ & 2 & Partial \\
$38-47$ & $160-167$ & 3 & Sufficient \\
48-above & 168 -above & 4 & Substantial \\
\hline
\end{tabular}

Source: USOE (2011a)

Individual schools in individual school districts throughout the state have different schedule types and the USOE did not have a continuous, accurate record of the schedule type for individual schools. The schedule types were therefore obtained by contacting the individual school districts and, in some cases, individual schools within the 39 school districts used in this study.

\section{Data Collection and Organization Procedures}

Before any data collection took place, permission to actually obtain data and conduct the research study was obtained from the Institutional Review Board of Utah State University (IRB), and permission was obtained to use State CRT data from the USOE. The IRB approval was granted as a Certificate of Exception, meaning that the data were from existing data and not connected directly to identifiable students (see Appendix A). Permission to use USOE CRT data was granted (see Appendix B). The individual schedule types in Utah schools, were public record, but had to be obtained by contacting each individual school district and requesting the schedule type information. 
The remainder of this section describes the data collection procedures that took place in order to complete the study. The Utah State Office of Education makes Algebra I CRT results available to the public, but acquiring the data in a useable format for the analysis required the assistance of the State Office’s data miner. A written request to the data miner in the USOE resulted in receiving the formal application for receiving data. After several e-mails and phone conversations the desired data and their specific organization were determined. The data for the 2010-2011 school year were organized by the USOE on an Excel spreadsheet by schools, grade levels, number of students, and CRT results as proficiency levels (see Table 5).

In this sample, row two indicates the school was School A, the grade is $10^{\text {th }}, 51$ students took the Algebra I CRT, 11 students scored a 1, 19 students scored a 2, 12 students scored a 3, and 9 students scored a 4 on the Proficiency Levels scale. Of the 51 students who took the test, $41 \%$ scored a 3 or 4 , which indicates "proficiency" (or passing) on this test. The spreadsheet from the USOE contained nine columns and 1,182 rows; 14 pages when printed.

Table 5

Sample of Data Received from USOE

\begin{tabular}{|c|c|c|c|c|c|c|c|}
\hline \multirow[b]{2}{*}{ School } & \multirow[b]{2}{*}{ Grade } & \multirow{2}{*}{$\begin{array}{l}\text { Number of } \\
\text { students }\end{array}$} & \multicolumn{4}{|c|}{ Proficiency levels } & \multirow{2}{*}{$\begin{array}{c}\% \text { of } \\
\text { Proficiency }\end{array}$} \\
\hline & & & 1 & 2 & 3 & 4 & \\
\hline \multirow[t]{3}{*}{ School A } & 10 & 51 & 11 & 19 & 12 & 9 & 41 \\
\hline & 11 & 20 & 7 & 11 & 2 & 0 & 10 \\
\hline & 12 & 11 & 2 & 4 & 2 & 3 & 45 \\
\hline \multirow[t]{3}{*}{ School B } & 07 & 68 & 0 & 0 & 18 & 50 & 100 \\
\hline & 08 & 320 & 0 & 32 & 134 & 154 & 90 \\
\hline & 09 & 134 & 3 & 32 & 63 & 36 & 74 \\
\hline
\end{tabular}

Source: USOE (2012). 
The data were received in an Excel file, as shown in Table 5. The data required considerable cleaning to be useful, answer the research questions, and be both readable and measurable by SPSS, the statistics software used for this study. Table 5 was arranged in a new spreadsheet, removing the "number of students" column from the original data set because SPSS would be able to self-generate that sum. Also excluded was the "\% of Proficiency” column because that information was not relevant to the research questions. The next step in cleaning the data was to examine the $300+$ schools in the data and determine if the number of students was fewer than 10 in order to maintain FERPA guidelines. Some of the schools were eliminated from the spreadsheet during this process because of their status as alternative schools (e.g., "LIGHTHOUSE LRN CTR [ALT]” in Carbon District). However, many alternative schools were unidentifiable by name and were removed from the data after districts and schools were contacted. The SPSS software requires that no data cells be blank. Some cells in the USOE data were blank cells that were meant to mean: no student in seventh grade scored a 2 on the CRT at School B. Each of the blanks had to be replaced with a "0.” The most problematic issue with the original data spreadsheet format was that the proficiency scores of 1-4 were in rows but SPSS reads/analyzes a separate variable (CRT score) as a column. So each of the CRT scores from the rows had to be transposed into parts of a variable column named CRT score (see Table 6).

Table 6 presents School A with $10^{\text {th }}-12^{\text {th }}$ grades but the CRT scores of 1 -4 are now vertical, not horizontal, and one row of $10^{\text {th }}$ graders became four rows. Overall, the number of rows on the cleaned spreadsheet totaled 2,679. 
Table 6

Sample of Cleaned Data in Excel

\begin{tabular}{lccc}
\hline School & Grade & CRT score & Frequency \\
\hline School A & 10 & 1 & 11 \\
& 10 & 2 & 19 \\
& 10 & 3 & 12 \\
& 10 & 4 & 9 \\
& 11 & 1 & 7 \\
& 11 & 2 & 11 \\
11 & 3 & 2 \\
& 11 & 4 & 0 \\
& 12 & 1 & 2 \\
& 12 & 2 & 4 \\
& 12 & 3 & 2 \\
& 12 & 4 & 3 \\
\hline
\end{tabular}

The data for schedule type for each school were collected by contacting each school district or school. Direct phone calls proved to be much more successful than emails. I started by calling each district office to determine if a curriculum, mathematics, or instructional specialist knew, for sure, the schedules types in a particular district. In smaller districts (e.g., Beaver, Millard) talking with one district person was sufficient to determine the schedule type for the district's algebra classes. Care was taken in indicating that the requested data were for the 2010-2011 school year and not the year in which the phone call was made. In many districts the district personnel did not know what the algebra schedules were for each school. For example, in one district, after being told by a district curriculum director "but I think some of the schools are different," all 25 different secondary schools were contacted individually by phone. In this district some Junior High Schools were on the A/B Block schedule and some of the Junior High Schools were on the traditional schedule. 
In addition to determining if a school used a particular schedule it was also necessary to determine each school's grading schedule. For example, if a secondary school used the four quarters/two semester grading schedule then a traditional or block schedule was in place. For this study, if a school was on a trimester schedule (three grading periods per year) the schools were not considered to have a traditional or a block schedule but one of the types of a trimester schedule. Telephone contact was made with one high school in regard to the nine students who had Algebra I CRT scores while on the trimester 3/3. These nine students were the only students in a Utah high school who were on the trimester 3/3 schedule. The circumstance of this situation was discussed with school administrator Erica Evans (pseudonym). After many phone calls the schedule was determined for each school in Utah in which the students took the Algebra I CRT for the 2010-2011 school year. A spreadsheet was created which contained the results of the Algebra I CRT, a listing of the schools in Utah, which met the study’s criteria, the grade levels within each of the schools, and the schedule type of each of these schools.

\section{Data Analysis Using SPSS}

Data analysis was designed to answer the two major research questions: (1) What is the relationship between mathematics instructional type and student scores on Utah's CRT for algebra, for all students? (2) What is the relationship between mathematics instructional type and student scores on Utah’s CRT for algebra, by individual grade levels?

The analysis of the data from the USOE and the school districts was completed 
using the SPSS statistical package. Through the multinomial logistic regression model the independent variables, schedule types and grade levels, were entered as categorical variables and were assigned value labels in SPSS. This allowed the independent variable grade to have separate designations of grades $7,8,9,10,11$, and 12 . The CRT proficiency scores were entered as the dependent variable as CRT score and were assigned value labels $1,2,3$, and 4 . It was necessary for clarity of the output data to have each of the CRT scores assigned a set of three dummy variable scores of zero in addition to the individual scores of 1, 2, 3, and 4 (see Table 7).

To answer the first research question, the independent variable data were grouped by schedule type for the entire state (all grades) and compared to the dependent variable of CRT score through a SPSS multinomial logistic regression analysis. To answer the second research question, an analysis was conducted for each grade level, sorted by schedule type, and compared to the CRT. For example, there was a statistical comparison between all Utah seventh graders on the A/B block compared to all Utah seventh graders on the traditional schedule compared to all students on each of the two types of trimester

Table 7

Sample of SPSS Input

\begin{tabular}{lcccccccc}
\hline & & Crt & & & \multicolumn{4}{c}{ (dummy codes) } \\
\cline { 6 - 9 } School & Grade & score & Frequency & Schedule & 1 & 2 & 3 & 4 \\
\hline School A & 10 & 1 & 11 & 1 & 1 & 0 & 0 & 0 \\
& 10 & 2 & 19 & 1 & 1 & 0 & 0 & 0 \\
& 10 & 3 & 12 & 1 & 1 & 0 & 0 & 0 \\
School C & 10 & 4 & 9 & 1 & 1 & 0 & 0 & 0 \\
& 8 & 1 & 1 & 3 & 0 & 0 & 1 & 0 \\
& 8 & 2 & 6 & 3 & 0 & 0 & 1 & 0 \\
& 8 & 3 & 38 & 3 & 0 & 0 & 1 & 0 \\
& 8 & 4 & 74 & 3 & 0 & 0 & 1 & 0 \\
\hline
\end{tabular}


schedules. The same comparisons were made for every grade. The purpose of this analysis was to determine the relationship, in terms of CRT scores, between seventhgrade students taught on the traditional schedule compared to seventh-grade students taught on the A/B block schedule compared to students taught on each of the two trimester schedules. By separating the data into grade levels many factors were somewhat equalized (e.g., number of years of mathematics classes, maturity level, age, and grade level of students in the same building). A comparison of a $7^{\text {th }}$ grader in an algebra class and a $10^{\text {th }}$ grader in an algebra class was not made as it would have several confounding factors. The SPSS input of data for a multinomial logistic regression design entailed the organization as displayed in Table 7.

Notice that School A has schedule type 1 (A/B Block schedule) and is dummy coded appropriately and that School C has schedule type 3 (trimester schedule when students attend algebra class every day all year) and is dummy coded appropriately. Once the table was created SPSS was used to analyze the data. The SPSS steps were: select analyze, regression, multinomial, the dependent variable will be CRT score, and the factors were grade level and schedule type. This analysis kept all grades as one group for research question one. Subsequent analyses disaggregated the data by individual grade levels for research question two. A change of schedule type in the mathematics classroom may result in changes in teacher practice and changes in classroom student behaviors which are important components in student learning. This study provided data to help determine if the schedule type itself was related to CRT scores, which is only one measure of student learning. 


\section{Additional Analyses with Independent Samples $t$ Tests for Percentages}

After the multinomial logistic regression was conducted with SPSS one of the outputs created was CRT scores for students separated by grade level and by schedule type. For each grade level the percentage of students who scored at each of the four different CRT scores 1 to 4 was displayed. For example, the output displayed the percentage of eighth-grade students who scored a CRT 4 for each of the schedule types. One important focus of the second research question was to determine the relationship between CRT scores and schedule type when the students were separated by grade level. The multinomial logistic regression model analysis established the ratio comparisons of one schedule type to another. However, these ratios in the study involve many pairs of ratios with each schedule compared to each grade level compared to each of the four CRT score designations. The results are statistically strong but too multi-layered to be accessible to the classroom practitioner. By examining the percentages from each separate grade level and schedule type, a clearer and more accessible picture of how well each schedule type compared to each other within the grade level was possible. This additional statistical analysis was conducted to assist in providing accurate statistics with an eye towards those who may use this research for positive educational change. For example, as schools and school district consider ways to improve algebra students’ CRT scores one aspect of the educational picture which is able to be adjusted is schedule type. If this research provides clear statistical relationships between CRT scores and schedule type, which $t$ tests can provide, then schools and school districts may consider the potential of adjusting schedule types. 
To further compare the relationship between CRT scores and schedule types an independent samples $t$ test for percent was selected and conducted. Because the SPSS outputs of the number of students with each CRT score were in percentages the dependent variable was continuous. The two assumptions to conduct independent samples $t$ tests are that the samples must be independent observations, which was the case here, and the population sampled should be normal (Glenberg \& Andrzejewski, 2008; Gravetter \& Wallnau, 2005). However, because of the very large sample size “violating this assumption has little practical effect on the results obtained for a $t$ statistic, especially when the sample size is relatively large” (Gravetter \& Wallnau, 2005, p. 239). So, by measuring one percent against another, and including the large sample size, a $t$ statistic was generated which also generated the $p$ value for each comparison.

In order to conduct this analysis I decided to measure the comparisons of the percentages of student who passed the CRT, not every CRT score from 1 to 4 . The State of Utah considered passing the CRT (a CRT score of 3 or 4) to be the determination if a school was making adequate yearly progress. This measure created the moniker of passing or failing schools and carried weight in the evaluation of success for schools and states under NCLB. By reducing the $t$ tests to a smaller number of comparisons, the unwieldy aspect of many comparisons was reduced to a much more comprehensible list which was still statistically robust.

For example, for eighth-grade students, the SPSS multinomial logistic regression created the following information: A/B schedule passing percentage $=82.7 \%$, traditional schedule passing percentage $=78.0 \%$, Trimester $3 / 3$ schedule passing percentage 
$=92.5 \%$. After combining the percentage information with the number of students who were included in each schedule type percentage, an independent samples $t$ test for percentages was conducted. The result displayed the differences as statistically significant, or not, and included the $t$ statistic, the degrees of freedom, and the $p$ value. Using the $t$ test was a beneficial step in understanding the relationship between CRT scores and schedule type when the students were separated by grade level. The $t$ test method, along with the multinomial logistic regression method, went to the heart of the second research question. 


\section{CHAPTER IV}

\section{RESULTS}

\section{Overview of Results}

The organization and analysis of the data was centered on the two research questions: (1) What is the relationship between mathematics instructional schedule type and student scores on Utah's CRT for algebra, for all students, and (2) What is the relationship between mathematics instructional schedule type and student scores on Utah’s CRT for algebra, by individual grades levels? In this chapter the results are organized and presented. The first part of this chapter presents and discusses the data as they were compiled and placed into spreadsheets. The next section interprets the computed data and resultant data displays. A portion of the analysis was based on an independent samples $t$ test, which was conducted as a comparison of the percentage of students separated by grade level and schedule type. Tables are used to summarize the results of the data collection, trends in the data set, and provide a statistical summary of the data.

In addition to the schedule types described in Chapter III, two additional schedule types became evident after the data were collected. The first was the Trimester 3/3 schedule in which the students have the school year divided into three grading periods, or trimesters. The 3/3 designation indicates that the students attended their algebra class for all three of the grading periods; which makes that particular schedule similar to a traditional schedule. The second additional schedule type was the Trimester 2/3, which 
indicates that the school had the grading period divided into three grading periods but the students only attended their algebra class for two out of the three grading periods. This research did not further separate the trimester $2 / 3$ schedule into which two of the three trimesters each student attended. In both of these trimester schedule types the students attended their algebra class every day. This is unlike a block schedule in which students attend algebra class every other day. As the individual districts and schools were contacted by the researcher it became clear that daily algebra attendance was not the same as a traditional schedule if the school used trimester grading for the school year. Some phone calls were remade to ensure that the data on each of the schedule types were categorized correctly. One high school was removed from the data set because some of the students on their trimester schedule took algebra for two of the trimesters (2/3 trimester) and some of the students took algebra for all three of the trimesters (3/3 trimester), and some of the students tested out of the algebra class during the middle of the third trimester. Although the $4 \times 4$ block was discussed in the review of literature for this study, this schedule type was not included in the analysis of data because no school in Utah which conducted a CRT for Algebra I used that particular schedule type.

The number of students, by CRT score, schedule type, and grade level are displayed in Table 8. The table disaggregates the 46,790 students who were participants in this study.

As was expected before the data were collected, the CRT scores displayed in Table 8 were not normally distributed. Having the noncontinuous dependent variable not 
Table 8

Summary of Cases

\begin{tabular}{llrc}
\hline Variable & & \multicolumn{1}{c}{$N$} & Percentage \\
\hline CRT score & 1. minimal & 6,973 & 14.9 \\
& 2 partial & 11,903 & 25.4 \\
& 3 sufficient & 13,774 & 29.4 \\
& 4 substantial & 14,140 & 30.2 \\
Schedule type & A/B block schedule & 23,207 & 49.6 \\
& Traditional schedule & 20,478 & 43.8 \\
& Trimester 3/3 & 2,536 & 5.4 \\
& Trimester 2/3 & 569 & 1.2 \\
Grade level & Grade 7 & 3,340 & 7.1 \\
& Grade 8 & 16,145 & 34.5 \\
& Grade 9 & 15,008 & 32.1 \\
& Grade 10 & 9,796 & 20.9 \\
Valid & Grade 11 & 1,893 & 4.0 \\
Missing & Grade 12 & 608 & 1.3 \\
\hline
\end{tabular}

being normally distributed led to the use of the logistic regression. Having two independent variables, grade level and schedule type, led to the use the multinomial logistic regression analysis of the data. The majority of the CRT scores (59.6\%) were either a 3 or 4 and considered a passing score on the Algebra I CRT by the Utah State Office of Education. The number of students who were taught algebra on the block schedule (49.6\%) or the traditional schedule (43.8\%) was over $90 \%$ of the students in the data set. Recall that the term traditional schedule is only in reference to a schedule type wherein the students meet every school day in a particular class and is not a reference to 
the type of instruction or mathematical content from any particular era. All six grade levels considered for inclusion in this study had some students represented, with $8^{\text {th }}$ grade (34.5\%) being the largest percentage of students and $12^{\text {th }}$ grade having the smallest percentage of students (1.3\%). The data's organization and analysis was completed so that all 46,790 students in the study were accounted for in the SPSS output analysis.

\section{Statistical Output and Analysis for Research Question 1}

The first research question for this study examined the relationship between instructional schedule type and students Algebra I CRT scores. To answer this question I organized the data through SPSS and determined the number and percent of students who scored each of the 1 to 4 CRT scores who were being instructed on each of the four Algebra I schedule types. The dependent variable, CRT scores, were categorical and they were also ordinal. This is important because it meant, for example, that a CRT score of " 3 ” is higher than a score of " 2. " Students with scores of 3 or 4 scored higher on the CRT than those with scores of 1 or 2 . Table 9 displays the ordinal CRT scores separated by the four schedule types. A study of Table 9 seems to indicate that the trimester 3/3 schedule was the schedule most related with higher scores. For example, the highest CRT score of 4 was achieved by $49.4 \%$ of students who were instructed on a trimester $3 / 3$ schedule; achieved by $35.5 \%$ of students who were instructed on a traditional schedule; achieved by $24.0 \%$ of students who were instructed on a A/B block schedule; and achieved by $9.1 \%$ of students who were instructed on a trimester $2 / 3$ schedule. However, the grade level of those students who were instructed on the trimester $3 / 3$ schedule was primarily in grades 
Table 9

Summary of CRT Scores by Schedule for All Algebra Students

\begin{tabular}{lcc}
\hline Schedule type & $\begin{array}{r}\text { Number of students with } \\
\text { each CRT score }\end{array}$ & $\begin{array}{c}\text { Percent by } \\
\text { schedule }\end{array}$ \\
\hline A/B block & $1=5,145$ & 22.2 \\
$2=6,648$ & 28.6 \\
$3=5,819$ & 25.1 \\
$4=5,568$ & 24.0 \\
Traditional schedule & Total $=23,207$ & 100 \\
$1=1,511$ & 7.4 \\
$2=4,638$ & 22.6 \\
$3=7,062$ & 34.5 \\
$4=7,267$ & 35.5 \\
Trimester 3/3 & Total $=20,478$ & 100 \\
$1=120$ & 4.7 \\
$2=361$ & 14.2 \\
$3=802$ & 31.6 \\
$4=1,253$ & 49.4 \\
Trimester 2/3 & $1=2,536$ & 100 \\
& $2=229$ & 34.6 \\
3 & $=91$ & 40.2 \\
$4=52$ & 16.0 \\
Total $=569$ & 9.1 \\
& & 100 \\
\hline
\end{tabular}

7, 8 , and 9 and those grade levels scored the highest on the CRT. The CRT score of 4 was achieved by $49.4 \%$ (1253 students) on the trimester 3/3 schedule but those students who scored lowest on the CRT, by grade, were $11^{\text {th }}$ and $12^{\text {th }}$ graders who were not instructed on the trimester 3/3 schedule. This result points to the importance of interpreting these data in context.

The SPSS output that addresses statistical significance is shown in Tables 10 and 11. As with all multinomial logistic regression analyses the nominal variables are 
Table 10

Multinomial Logistic Regression Model Fitting, Using Schedule Type

\begin{tabular}{lcccc}
\hline & Model criteria & \multicolumn{3}{c}{ Likelihood ratio tests } \\
\cline { 3 - 5 } Model & $-2 \log$ likelihood & Chi-square & $d f$ & Sig. \\
\hline Intercept only final & 99.739 & .000 & 0 & \\
& $3.717 \mathrm{E} 3$ & $3.617 \mathrm{E} 3$ & 9 & .000 \\
\hline
\end{tabular}

Table 11

Multinomial Logistic Regression Using Schedule Type

\begin{tabular}{|c|c|c|c|c|c|c|c|}
\hline \multirow[b]{2}{*}{ CRT score } & & \multirow[b]{2}{*}{ B } & \multirow[b]{2}{*}{ Std. error } & \multirow[b]{2}{*}{ Sig. } & \multirow[b]{2}{*}{$\operatorname{Exp}(B)$} & \multicolumn{2}{|c|}{$\begin{array}{l}\text { 95\% confidence } \\
\text { interval for } \operatorname{Exp}(\mathrm{B})\end{array}$} \\
\hline & & & & & & $\begin{array}{l}\text { Lower } \\
\text { bound }\end{array}$ & $\begin{array}{l}\text { Upper } \\
\text { bound }\end{array}$ \\
\hline \multirow[t]{5}{*}{ Partial } & Intercept & .151 & .097 & .121 & & & \\
\hline & $\begin{array}{l}\text { Schedule } 1 \\
\text { (A/B Block) }\end{array}$ & .110 & .099 & .267 & 1.116 & .919 & 1.355 \\
\hline & $\begin{array}{l}\text { Schedule } 2 \\
\text { (traditional) }\end{array}$ & .971 & .102 & .000 & 2.641 & 2.164 & 3.222 \\
\hline & $\begin{array}{l}\text { Schedule } 3 \\
\text { (trimester 3/3) }\end{array}$ & .951 & .143 & .000 & 2.588 & 1.954 & 3.427 \\
\hline & Schedule 4 & & & & & & \\
\hline \multirow[t]{5}{*}{ Sufficient } & Intercept & -.772 & .127 & .000 & & & \\
\hline & Schedule 1 & .895 & .128 & .000 & 2.448 & 1.904 & 3.148 \\
\hline & Schedule 2 & 2.314 & .130 & .000 & 10.118 & 7.844 & 13.051 \\
\hline & Schedule 3 & 2.672 & .160 & .000 & 14.468 & 10.571 & 19.803 \\
\hline & Schedule 4 & & & & & & \\
\hline \multirow[t]{5}{*}{ Substantial } & Intercept & -1.332 & .156 & .000 & & & \\
\hline & Schedule 1 & 1.411 & .157 & .000 & 4.100 & 3.013 & 5.578 \\
\hline & Schedule 2 & 2.903 & .158 & .000 & 18.220 & 13.356 & 24.856 \\
\hline & Schedule 3 & 3.678 & .183 & .000 & 39.558 & 27.643 & 56.609 \\
\hline & Schedule 4 & & & & & & \\
\hline
\end{tabular}

Note. The reference category is 1 minimal 
compared one to another. The CRT scores of 2, 3, and 4 are compared to a CRT score of 1 (the lowest score). By default the schedule types 1, 2, and 3 are compared to schedule type 4 (the trimester 2/3).

Table10 indicates that some of the variation in the dependent variable CRT scores was influenced by schedule type. The significance of $p<.0005$ suggests that the variations in the dependent variable were not caused by chance. The chi-square value of 3,617 ( $d f=9$ ), is a large value, which suggests that an assumption that each of the CRT scores for each schedule type would have equal amounts is incorrect.

Table 11 displays the comparison of schedule types 1 , 2, and 3 to schedule type 4 when separated by the four possible CRT scores. Included is the B value, Standard Error, Significance, $\operatorname{Exp}(\mathrm{B})$ and the 95\% confidence interval.

Table 11 reveals the numerical values of comparison from the logistic regression model analysis. The values for " $\mathrm{B}$ ” are an important aspect of the logistic regression model for this study, as they indicate the comparisons of each of the schedule types to the same value. The outputs are not compared to a linear model but to a logarithmic model with the natural $\log e$ being the base of the exponential model with its resultant odds ratios. For example, the B-value for a CRT score of partial with the A/B block schedule (from Table 11) is .110. That value is the exponent to be attached to the base $e$ in order to attain the numerator of the ratio; with a CRT score 1 as the denominator (the reference category). When $e$ is raised to the .110 power the result is 1.116 , which can be located in the same row of the table in the $\operatorname{Exp}(B)$ column. The $\operatorname{Exp}(B)$ column is very important in this model as it was an indicator of the relative (ratios) size of one of the independent 
variables to another independent variable in regard to the dependent variable. In Table 11, the $\operatorname{Exp(B)~column~for~CRT~partial~scores~in~the~A/B~block~schedule~has~values~of~}$ 1.116, 2.641, and 2.588; which indicates that the greatest of the three values (2.641) matches the percent of correct answers from Table 9. By surveying the Exp(B) column it can be seen how the schedule types compared one to another for each of the listed schedule types and each of the CRT scores. The value of having this SPSS output in regard to the first research question was that it showed the relative CRT scores in regard to schedule type and it has the statistical significance value. Note how the $\operatorname{Exp}(B)$ values fluctuate, meaning the CRT scores for each schedule type also fluctuated. The model was statistically significant for all variables except the ratio of the A/B block schedule (CRT partial to minimal ratio) compared to the trimester 2/3 schedule (CRT partial to minimal ratio). So for fifteen of the sixteen ratios, only one ratio was not statistically significantly different. Throughout Table 11 the standard errors are small to medium and generally influenced by the large sample size (Gravetter \& Wallnau, 2005).

After the multinomial logistic regression was conducted a portion of the output listed the proportion of students who scored a CRT 1, 2, 3, or 4 from each of the four schedule types. Because the number of students was included, as well as the proportion of student scores, an independent samples $t$ test was conducted to determine if the differences in the student scores for each schedule type were statistically significant. The USOE measured passing the Algebra I CRT as scoring a 3 or 4 . The $t$ tests measured those who passed each of the four schedules against all of the other passing scores for each schedule type—six $t$ tests in all. By utilizing this method an independent samples $t$ 
test was able to measure the continuous variable of percent scores in relation to the four individual schedule types. Table 9 shows that the students who were taught on the trimester 3/3 schedule scored the highest, followed by the traditional, $\mathrm{A} / \mathrm{B}$ block and trimester 2/3 schedules. The number of student scores in the data set were large (23,207 A/B block, 20,478 traditional) so any percent difference was likely to be statistically significant. The independent samples $t$ test results found all differences between schedule types were statistically significant; with the two most common schedules, A/B block and traditional, having a $t$ statistic of 34.092 and a significance of $p<.0005$.

A multinomial logistic regression analysis was conducted to determine the relationship between Utah Algebra I CRT scores and the school schedule types in which the students were taught. An analysis of 46,790 cases and the test of the full model against a constant only model was statistically significant, indicating that the predictor variables, as a group, were reliably distinguished between the four different CRT scores (chi-square $=3.617 \mathrm{E} 3, p<.0005$ with $d f=9$ ). Nagelkirke's $R^{2}$ of .284 indicated a moderate relationship between predictors and CRT scores for the entire model. $\operatorname{Exp(B)}$ values ranged from 1.116 to 39.558 when the CRT score of 1 was the reference category. An independent samples two-tailed $t$ test was conducted between the CRT scores of the four schedule types. The percentage of students passing the CRT in each schedule type from highest to lowest were: trimester $3 / 3$ schedule ( $81 \%$ passed), traditional schedule (70\% passed), A/B block schedule (49\% passed) and trimester 2/3 schedule (25\% passed). The $t$-statistic comparisons for adjacent schedule types (greatest to least scores) were 10.32, 34.09, and 5.71; the significance was $p<.0005$ in each case. The 
differences in the percentage of students who passed the CRT were statistically significant.

\section{Statistical Output and Analysis for Research Question 2}

The second research question determined the relationship between mathematics instructional schedule type and student scores on Utah's CRT for Algebra I, when the individual grade levels of students were taken into account. In order to answer this question I organized and analyzed the data using SPSS and a partial analysis using independent samples $t$ tests for percentages. The analysis of multinomial logistic regression was completed as an odds ratio which compared one value to another (Garson, 2011). When executing the analysis on SPSS one of the variables must be determined to be the reference category variable (Chen \& Hughes, 2004). In my analysis I chose the CRT score of 1 (minimal) as the reference category because I wanted to have the highest, and most common, scores 2-3-4 to be observed scores. This meant that a ratio of a CRT score of 2 was compared to a 1 ; a 3 was compared to a 1 ; and a 4 was compared to a 1 . Each of these comparisons was completed by separate grade levels and by different schedule types. One table was used for each grade level as this would direct the data analysis to the second research question, which was determining the relationship between CRT scores, schedule type and individual grade levels. Table 12 displays the percentage of students by grade who passed (scored a 3 or 4 ) on the CRT and the total number of students per grade. 
Table 12

Percentage of Students Who Passed the CRT by Grade Level

\begin{tabular}{lcr}
\hline Grade level & $\begin{array}{r}\text { Percentage passing } \\
\text { (score of 3 or 4) }\end{array}$ & \multicolumn{1}{c}{$N$} \\
\hline Grade 7 & 95.7 & 3340 \\
Grade 8 & 80.7 & 16,145 \\
Grade 9 & 52.8 & 15,008 \\
Grade 10 & 31.7 & 9796 \\
Grade 11 & 24.0 & 1893 \\
Grade 12 & 33.4 & 608 \\
\hline
\end{tabular}

When only considering grade level, and the percentage of students who passed the Algebra I CRT, the trend was for a large percent of $7^{\text {th }}$ graders passing and each subsequent grade having a reduction in the number who passed the CRT, until $12^{\text {th }}$ grade (see Table 12). Table 12 illustrated why schedule type and CRT scores needed to be separated by grade level to have meaning. For example, no seventh-, eighth-, or ninthgrade students were taught Algebra I using the trimester 2/3 schedule. Table 13 displays the multinomial logistic regression statistical output when grade level was the only independent variable measured, not schedule type.

Table 13 suggests that some of the variation in the dependent variable CRT scores was influenced by just grade level. The significance of $p<.0005$ indicates the variations in the dependent variable were not caused by chance. The chi-square test, with a large value of 13,830, suggested that CRT scores by grade level were not equally distributed. The pseudo $R^{2}$ designation is an acknowledgement that a true $R^{2}$ value does not exist in a logistic regression model but the typical measure in a logistic regression model which is most similar to $R^{2}$ is the Nagelkerke value. In the model the Nagelkerke $R^{2}$ was .274, 
Table 13

Multinomial Logistic Regression Model Fitting, Using Grade Level Only

\begin{tabular}{lcccc}
\hline & Model criteria & \multicolumn{3}{c}{ Likelihood ratio tests } \\
\cline { 3 - 5 } Model & -2 log likelihood & Chi-Square & $d f$ & Sig. \\
\hline Intercept only & 143.443 & .000 & 0 & \\
Final & $1.398 \mathrm{E} 4$ & $1.383 \mathrm{E} 4$ & 9 & .000 \\
Pseudo $R^{2}:$ & Nagelkerke $=.274$ & & & \\
\hline
\end{tabular}

which means that $27.4 \%$ of the variation in the dependent variable can be explained by the independent variable grade level (UCLA Statistics, 2007). Considering the chi-square value and the significance level, just grade level alone is sufficient to explain the differences in students' scores on the CRT for Algebra I.

\section{Multinomial Logistic Regression for All Grades}

The data were organized and a multinomial logistic regression analysis was conducted with CRT scores selected as the dependent variable and both schedule type and grade level selected as independent variables. This allowed an analysis to be conducted, which revealed the relationship between CRT scores and individual grade levels with the factor of schedule type included. Table 14 shows the summary of the Likelihood Ratio Tests provided by the SPSS analysis when both schedule type and grade level were included.

For Table 14, the independent variables being categorical are compared as ratios. These tests determined the likelihood that the differences in the comparisons of the ratios of CRT scores by grade occurred by chance. Table 14 is a measure of student CRT scores as the dependent variable and grade level $\left(7^{\text {th }}-12^{\text {th }}\right)$ and schedule types as the independent 
Table 14

Likelihood Ratio Tests for CRT Scores with Schedule Type and Grade Level

\begin{tabular}{lcccc}
\hline & Model Criteria & \multicolumn{3}{c}{ Likelihood ratio tests } \\
\cline { 3 - 5 } Effect & $\begin{array}{c}\text { log likelihood of } \\
\text { reduced model }\end{array}$ & Chi-Square & $d f$ & Sig. \\
\hline Intercept & 609.960 & & 0 & \\
Schedule & $1.182 \mathrm{E} 3$ & 571.8 & 9 & .000 \\
Grade level & $1.140 \mathrm{E} 4$ & $1.079 \mathrm{E} 4$ & 15 & .000 \\
Pseudo $R^{2}$ & Nagelkerke $=.284$ & & & \\
\hline
\end{tabular}

variables. This table suggests that some of the variation in the dependent variable CRT score ratios was influenced by grade level and by schedule type. In the model the Nagelkerke $R^{2}$ was .284 which indicated that $28.4 \%$ of the variation in the dependent variable could be explained by the independent variables. The chi-square values and the significance of $p<.0005$ suggested that the variations in the dependent variable were not caused by chance. In other words, either grade level or schedule type was sufficient to explain the differences in students' scores on the CRT.

Table 15 reports the $\operatorname{Exp}(\mathrm{B})$, standard error and significance levels after the SPSS multinomial logistic regression analysis was conducted. The values included in Table 15 only included grade level because the inclusion of the values for the schedule type would have been redundant with the data in Table 11.

Table 15 displays the ratios between CRT scores by grade level. For example, for a CRT score of 4, substantial, the $\operatorname{Exp(B)~value~was~} 362.461$ for seventh-grade students. This means a seventh-grade student was 362 times more likely to score a CRT 4 than to score a CRT 1 (the reference category); an eighth-grade student was 33.636 times more 
Table 15

Multinomial Logistic Regression Using Schedule Type and Grade Level

\begin{tabular}{llrccc}
\hline CRT score & Grade & \multicolumn{1}{c}{ B } & Std error & Sig. & Exp(B) \\
\hline 2 partial & Grade 7 & 2.013 & .272 & .000 & 7.486 \\
& Grade 8 & 1.625 & .113 & .000 & 5.080 \\
& Grade 9 & .918 & .105 & .000 & 2.504 \\
& Grade 10 & .476 & .104 & .000 & 1.610 \\
& Grade 11 & .116 & .114 & .000 & 1.123 \\
& Grade 12 & & & & \\
3 sufficient & Grade 7 & 3.898 & .264 & .000 & 49.320 \\
& Grade 8 & 2.601 & .121 & .000 & 13.482 \\
& Grade 9 & 1.175 & .115 & .000 & 3.239 \\
& Grade 10 & .218 & .114 & .056 & 1.244 \\
& Grade 11 & -.281 & .129 & .029 & .755 \\
& Grade 12 & & & & \\
4 substantial & Grade 7 & 5.893 & .271 & .000 & 362.461 \\
& Grade 8 & 3.516 & .140 & .000 & 33.636 \\
& Grade 9 & 1.196 & .135 & .000 & 3.307 \\
& Grade 10 & .033 & .135 & .805 & 1.034 \\
& Grade 11 & -.649 & .160 & .000 & .523 \\
& Grade 12 & & & & \\
\hline
\end{tabular}

Note. The reference categories are: 1 minimal and $12^{\text {th }}$ grade.

likely to score a CRT 4 than to score a CRT 1 . But an $11^{\text {th }}$-grade student was less likely (.523 to 1 ) to score a CRT 4 than a $12^{\text {th }}$-grade student. This table indicates strong, and significant, patterns in the ratios of CRT scores by grade level. The only grade level that did not have significant differences to the reference grade $\left(12^{\text {th }}\right.$ grade) is $10^{\text {th }}$ grade. The significance was $p=.805$ for CRT 4 scores and $p=.056$ for CRT 3 scores. All the other grades and CRT scores had $p<.0005$. The $\operatorname{Exp(B)}$ column is particularly insightful because it shows an equal measure from each grade to each of the other grades. This only shows the differences by grade level in CRT scores but does not show the differences by grade level compared to schedule type. 


\section{Individual Grade-Level Comparisons With Regard to Schedule Type}

The analysis of the data through a multinomial logistic regression using SPSS created separate grade level analyses. By analyzing the data, with CRT scores as the dependent variable and grade level (with six separate levels) as the independent variable, the resultant output calculated the number of students from each grade level and each schedule type with each of the four CRT scores. Table 15 displays all grade levels in comparison to each other but, starting with Table 16, each grade level is displayed separately. Table 16 reveals that seventh-grade students were taught on three different schedule types: A/B block, traditional, and trimester 3/3 schedules. The number of students, as well as the percentage of students, who scored each of the four CRT scores was separated by the three schedule types.

\section{Table 16}

Comparison of CRT Scores by Schedule Type for Seventh Grade

\begin{tabular}{llrc}
\hline Schedule type & CRT score & $N$ & Percent \\
\hline A/B block schedule & 1 minimal & 7 & 0.8 \\
$N=858$ & & & \\
& 2 partial & 41 & 4.8 \\
& 3 sufficient & 144 & 16.8 \\
& 4 substantial & 666 & 77.6 \\
Traditional schedule & 1 minimal & 11 & 0.5 \\
$N=2,398$ & & & \\
& 2 partial & 86 & 3.6 \\
& 3 sufficient & 525 & 21.9 \\
& 4 substantial & 1,776 & 74.9 \\
Trimester 3/3 & 1 minimal & 0 & 0 \\
$N=84$ & & & \\
& 2 partial & 0 & 0 \\
& 3 sufficient & 10 & 11.9 \\
& 4 substantial & 74 & 88.1 \\
\hline
\end{tabular}


Table 16 displays the consistent clustering of higher scores (3 or 4) for any of the schedule types. Note that only 84 students in seventh grade were taught on the trimester 3/3 schedule compared to 858 students in the seventh grade taught on the A/B block schedule and 2,398 students in the seventh grade who were taught on the traditional schedule. There were not any seventh-grade students who were taught on the trimester 2/3 schedule who took the Algebra I CRT for the 2010-2011 school year. The question considered here was whether the differences in scores, when also taking into account the differences in the number of students in each category, were statistically significant.

Table 17 shows the $t$ test comparisons between schedule types for seventh-grade students. In order to determine if there was a statistically significant difference between the CRT scores by schedule type a two-tailed $t$ test for independent samples was conducted. Because a $t$ test only measures two samples at a time, a total of three tests were used to measure all differences. In Utah the CRT scores of 3 or 4 are indicators that a student, or a school, passed the Algebra I CRT. The $t$ tests for these data compared passing CRT scores of A/B block to traditional, traditional to trimester 3/3, and trimester 3/3 to A/B block. This analysis sought to determine if there were statistically significant differences between CRT scores when the scores were separated by schedule types and each grade level had an individual analysis. The values generated were comparisons between every schedule type used by seventh-grade students and display the t-statistic of the comparisons and the significance as a $p$ value.

Table 17 helped address the question of whether one schedule type results in higher CRT scores than another schedule type. For the seventh-grade students the passing 
Table 17

Independent $\mathrm{t}$ Tests Comparing Percentages for Seventh Grade for All Schedule Types

\begin{tabular}{llcc}
\hline $\begin{array}{l}\text { Percentage of passing by } \\
\text { schedule type (score of } 3 \text { or 4) }\end{array}$ & $\begin{array}{c}\text { Schedule types: Comparison } \\
\text { of passing scores }\end{array}$ & $t$ statistic & Two-tailed significance \\
\hline A/B Block $=94.4$ & Block to traditional & 1.906 & .0509 \\
Traditional $=96.0$ & Block to trimester 3/3 & 2.226 & .0263 \\
Trimester 3/3=100 & Traditional to trimester 3/3 & 1.869 & .0618 \\
\hline
\end{tabular}

percentage was very high for all three schedule types. The only two schedules with a significant difference were the A/B block schedule and trimester 3/3 ( $p=.0263)$, which suggests that the trimester $3 / 3$ was related to a higher score when compared to the $A / B$ block. Table 18 compares eighth-grade students' CRT scores for three schedules types, as with the seventh-grade students, no students were taught in the trimester $2 / 3$ schedule. Table 18 reveals that eighth-grade students were taught on three different schedule types: A/B block, traditional, and trimester $3 / 3$ schedules. The number of students, as well as the percentage of students, who scored each of the four CRT scores was separated by the three schedule types.

Table 18 shows that the percentages of eighth-grade students who passed the CRT, by schedule, were trimester 3/3 (92.5\%), A/B block (82.7\%), and traditional (78.0\%). Compared to seventh-grade students, the percentage of students on the traditional schedule who passed was $18 \%$ lower.

Table 19 shows the $t$-test comparisons between schedule types for eighth-grade students. In order to determine if there was a statistically significant difference between the CRT scores by schedule type a two-tailed $t$ test for independent samples was 
Table 18

Comparison of CRT Scores by Schedule Type for Eighth Grade

\begin{tabular}{llrc}
\hline Schedule type & \multicolumn{1}{c}{ CRT score } & $N$ & Percentage \\
\hline A/B block schedule & 1 minimal & 202 & 4.1 \\
$N=4,919$ & & & \\
& 2 partial & 646 & 13.1 \\
& 3 sufficient & 1467 & 29.8 \\
& 4 substantial & 2604 & 52.9 \\
Traditional schedule & 1 minimal & 341 & 3.5 \\
$N=9,775$ & & & \\
& 2 partial & 1812 & 18.5 \\
& 3 sufficient & 3673 & 37.6 \\
Trimester 3/3 & 4 substantial & 3949 & 40.4 \\
$N=1,451$ & 1 minimal & 10 & 0.7 \\
& & & \\
& 2 partial & 98 & 6.8 \\
& 3 sufficient & 433 & 29.8 \\
& 4 substantial & 910 & 62.7 \\
\hline
\end{tabular}

Table 19

Independent t Tests Comparing Percentages for Eighth Grade for All Schedule Types

\begin{tabular}{llcc}
\hline $\begin{array}{l}\text { Percentage of passing by } \\
\text { schedule type (score of 3 or 4) }\end{array}$ & $\begin{array}{c}\text { Schedule types: Comparison } \\
\text { of passing scores }\end{array}$ & $\begin{array}{c}t \text { statistic } \\
\text { A }\end{array}$ & $\begin{array}{c}\text { Two-tailed } \\
\text { significance }\end{array}$ \\
\hline A/B Block $=82.7$ & Block to traditional & 6.012 & .000 \\
Traditional $=78.0$ & Block to trimester 3/3 & 8.753 & .000 \\
Trimester 3/3 $=92.5$ & Traditional to trimester 3/3 & 12.289 & .000 \\
\hline
\end{tabular}

conducted. The values generated were comparisons between every schedule type used by eighth-grade students and display the $t$ statistic of the comparisons and the significance as a $p$ value.

Table 19 shows that the percent of eighth-grade students who passed the CRT was lower than it was for the seventh-grade students. In addition, the difference between the 
percentages of passing was greater. There was a significant difference between each of the three schedule types $(p<.0005)$ with the greatest percent of passing being the trimester 3/3 schedule followed by the A/B block and then the traditional schedule.

The ninth-grade students also were only taught Algebra on three different schedule types: A/B block, traditional, and trimester 3/3 schedules. The percentage of students passing the CRT, continuing the trend, was lower in ninth grade than the two previous grade levels. Table 20 compares ninth-grade students' CRT scores for three schedules types. As with the seventh- and eighth-grade students, no students were taught in the trimester $2 / 3$ schedule. The number of students, as well as the percentage of students, who scored each of the four CRT scores was separated by the three schedule types.

Table 20

Comparison of CRT Scores by Schedule Type for Ninth Grade

\begin{tabular}{llrc}
\hline Schedule type & \multicolumn{1}{c}{ CRT score } & $N$ & Percentage \\
\hline A/B block schedule & 1 minimal & 1,250 & 18.4 \\
$N=6,799$ & & & \\
& 2 partial & 2,150 & 31.6 \\
& 3 sufficient & 2,116 & 31.1 \\
& 4 substantial & 1,283 & 18.9 \\
Traditional schedule & 1 minimal & 902 & 12.5 \\
$N=7,217$ & & & \\
& 2 partial & 2,415 & 33.5 \\
& 3 sufficient & 2,566 & 35.6 \\
& 4 substantial & 1,334 & 18.5 \\
Trimester 3/3 & 1 minimal & 108 & 10.9 \\
$N=992$ & & & \\
& 2 partial & 260 & 26.2 \\
& 3 sufficient & 356 & 35.9 \\
& 4 substantial & 268 & 27.0 \\
\hline
\end{tabular}


Table 20 shows that the percentages of ninth-grade students who passed the CRT, by schedule type, were trimester 3/3 (62.9\%), traditional (54.1\%) and A/B block (50,0\%). Compared to earlier grades the percentage of students passing the CRT was reduced for every schedule type.

Table 21 shows the $t$-test comparisons between schedule types for ninth-grade students. In order to determine if there was a statistically significant difference between the CRT scores by schedule type a two-tailed $t$ test for independent samples was conducted. The values generated were comparisons between every schedule type used by ninth-grade students and display the t-statistic of the comparisons and the significance as a $p$ value.

Table 21 shows the differences in passing rates was statistically significant $(p<$ .0005) between each of the three schedule types. Because the number of students included in the study was large even a difference of four percentage points can be significant.

Table 22 compares $10^{\text {th }}$-grade students' CRT scores for all four schedules types. For the first time a grade level had students taught on the trimester 2/3 schedule.

Table 21

Independent t Tests Comparing Percentages for Ninth Grade for All Schedule Types

\begin{tabular}{llcc}
\hline $\begin{array}{l}\text { Percentage of passing by } \\
\text { schedule type (score of 3 or 4) }\end{array}$ & $\begin{array}{c}\text { Schedule types: Comparison } \\
\text { of passing scores }\end{array}$ & $t$ statistic & $\begin{array}{c}\text { Two-tailed } \\
\text { significance }\end{array}$ \\
\hline A/B Block $=50.1$ & block to traditional & 3.669 & .000 \\
Traditional $=54.1$ & block to trimester 3/3 & 5.883 & .000 \\
Trimester 3/3= 62.9 & traditional to trimester 3/3 & 3.871 & .000 \\
\hline
\end{tabular}


Although each of the four studied schedule types occurred for $10^{\text {th }}$-grade students, only a total of five $10^{\text {th }}$-grade students were taught algebra on the trimester $3 / 3$ schedule. The number of students, as well as the percentage of students, who scored each of the four CRT scores was separated by the four schedule types.

Table 22 reveals the continuing trend of fewer students passing the CRT as the grade level increases. For the first time the traditional schedule had the highest percent of students passing the CRT (47.9\%) followed by the A/B block schedule (30.2\%) and the trimester 2/3 schedule (25.9\%).

Table 22

Comparison of CRT Scores by Schedule Type for $10^{\text {th }}$ Grade

\begin{tabular}{llrc}
\hline Schedule type & CRT score & $N$ & Percentage \\
\hline A/B Block schedule & 1 minimal & 2,739 & 32.6 \\
$N=8,404$ & & & \\
& 2 partial & 3,125 & 37.2 \\
& 3 sufficient & 1,705 & 20.3 \\
& 4 substantial & 835 & 9.9 \\
Traditional schedule & 1 minimal & 202 & 22.1 \\
$N=915$ & & & \\
& & & \\
& 2 partial & 275 & 30.1 \\
& 3 sufficient & 255 & 27.9 \\
Trimester 3/3 & 4 substantial & 183 & 20.0 \\
$N=5$ & 1 minimal & 1 & 20.0 \\
& & & \\
& 2 partial & 1 & 20.0 \\
Trimester 2/3 & 3 sufficient & 2 & 40.0 \\
$N=472$ & 4 substantial & 1 & 20.0 \\
& 1 minimal & 163 & 34.5 \\
& & & \\
& 2 partial & 187 & 39.6 \\
& 3 sufficient & 81 & 17.2 \\
\hline
\end{tabular}


Table 23 shows the $t$-test comparisons between schedule types for $10^{\text {th }}$-grade students. In order to determine if there was a statistically significant difference between the CRT scores by schedule type a two-tailed $t$ test for independent samples was conducted. The values generated were comparisons between every statistically viable schedule type used by $10^{\text {th }}$-grade students and display the $t$ statistic of the comparisons and the significance as a $p$ value. Because of the small number of students (5) who were taught Algebra on the trimester 3/3 schedule that group was not included in the $t$ tests of differences of percentages of passing CRT scores.

Table 23 reveals that the differences in scores were statistically significant between the block and the traditional, and the traditional and the trimester $2 / 3(\mathrm{p}<.000)$, but not between the block and the trimester $2 / 3(p=.312)$. This indicates that the difference in passing percentages between the students who took their algebra CRT on the A/B block schedule and trimester $2 / 3$ schedule had a greater than $5 \%$ chance of being caused by chance. With fewer total students taking the algebra CRT, compared to previous grades, the percentage differences of passing scores between schedule types needed to have been greater to have been statistically significant.

Table 23

Independent $\mathrm{t}$ Tests Comparing Percentages for $10^{\text {th }}$ Grade for All Schedule Types

\begin{tabular}{llcc}
\hline $\begin{array}{l}\text { Percentage of passing by } \\
\text { schedule type (score of 3 or 4) }\end{array}$ & $\begin{array}{c}\text { Schedule types: Comparison } \\
\text { of passing scores }\end{array}$ & $t$ statistic & $\begin{array}{c}\text { Two-tailed } \\
\text { significance }\end{array}$ \\
\hline A/B block $=30.2$ & Block to traditional & 7.287 & .000 \\
Traditional $=47.9$ & Block to trimester 2/3 & 1.012 & .312 \\
Trimester 2/3= 25.9 & traditional to trimester 2/3 & 4.340 & .000 \\
\hline
\end{tabular}


The students in the $11^{\text {th }}$ grade (Table 24 ) represented all four studied schedule types, but again, the number of student who were taught on the trimester 3/3 was low (4 students). The number of students, as well as the percentage of students, who scored each of the four CRT scores was separated by the four schedule types.

Table 24 shows the continuing trend that the passing scores on the $11^{\text {th }}$-grade CRT were lower than the previous grade levels. The passing percentages, by schedule, were traditional (42\%), A/B block (22.9\%), and trimester 2/3 (11.0\%). The total number of students in the $11^{\text {th }}$ grade who took the Algebra I CRT dropped significantly compared to earlier grade levels (e.g., $8^{\text {th }}$-grade students $=16,145$ and $11^{\text {th }}$-grade students $=1,893$ ) .

Table 24

Comparison of CRT Scores by Schedule Type for $11^{\text {th }}$ Grade

\begin{tabular}{llcc}
\hline Schedule type & CRT score & $N$ & Percentage \\
\hline A/B block schedule & 1 minimal & 741 & 43.7 \\
$\mathrm{~N}=1,694$ & & & \\
& 2 partial & 566 & 33.4 \\
& 3 sufficient & 272 & 16.1 \\
& 4 substantial & 115 & 6.8 \\
Traditional schedule & 1 minimal & 33 & 27.7 \\
$\mathrm{~N}=$ 85 & & & \\
& 2 partial & 36 & 30.3 \\
& 3 sufficient & 35 & 29.4 \\
Trimester 3/3 & 4 substantial & 15 & 12.6 \\
$\mathrm{~N}=4$ & 1 minimal & 1 & 25.0 \\
& & & \\
& 2 partial & 2 & 50.0 \\
& 3 sufficient & 1 & 25.0 \\
Trimester 2/3 & 4 substantial & 0 & 0 \\
$\mathrm{~N}=76$ & 1 minimal & 26 & 34.2 \\
& & & \\
& 2 partial & 34 & 44.7 \\
& 3 sufficient & 8 & 10.5 \\
& 4 substantial & 8 & 10.5 \\
\hline
\end{tabular}


Table 25 displays the $t$ test comparisons between schedule types for $11^{\text {th }}$-grade students. In order to determine if there was a statistically significant difference between the CRT scores by schedule type a two-tailed $t$ test for independent samples was conducted. The values generated were comparisons between every statistically viable schedule type used by $11^{\text {th }}$-grade students and display the t-statistic of the comparisons and the significance as a $p$ value. Because of the small number of students (four) who were taught Algebra on the trimester 3/3 schedule that group was not included in the $t$ tests of differences of percentages of passing CRT scores.

The relatively low number of $11^{\text {th }}$-grade students who took the Algebra I CRT has the results of the $t$ test differences displayed in Table 25. The differences were statistically significant between the block and the traditional $(p<.005)$, and the traditional and the trimester $2 / 3(p<.05)$, but not between the block and the trimester $2 / 3$ $(p=2.641)$. The percentage of students passing the algebra CRT again was lower than previous grades.

Table 26 displays the comparison of CRT scores for $12^{\text {th }}$-grade students. Three types of schedules are represented as no $12^{\text {th }}$-grade students were taught on the trimester 3/3 schedule who also took the Algebra I CRT. The number of students, as well as the

Table 25

Independent t Tests Comparing Percentages for 11th Grade for All Schedule Types

\begin{tabular}{llcc}
\hline $\begin{array}{l}\text { Percentage of passing by } \\
\text { schedule type (score of } 3 \text { or 4) }\end{array}$ & $\begin{array}{c}\text { Schedule types: Comparison } \\
\text { of passing scores }\end{array}$ & $t$ statistic & $\begin{array}{c}\text { Two-tailed } \\
\text { significance }\end{array}$ \\
\hline A/B Block $=22.9$ & Block to traditional & 2.932 & .004 \\
Traditional $=42.0$ & Block to trimester 2/3 & 1.118 & .2641 \\
Trimester 2/3= 11.0 & traditional to trimester 2/3 & 2.271 & .0265 \\
\hline
\end{tabular}


Table 26

Comparison of CRT Scores by Schedule Type for $12^{\text {th }}$ Grade

\begin{tabular}{llll}
\hline \multicolumn{1}{c}{ Schedule type } & \multicolumn{1}{c}{ CRT score } & \multicolumn{1}{c}{$N$} & Percentage \\
\hline $\begin{array}{l}\text { A/B block schedule } \\
\mathrm{N}=533\end{array}$ & 1 minimal & 206 & 39.6 \\
& & & \\
& 2 partial & 147 & 27.6 \\
& 3 sufficient & 115 & 21.6 \\
& 4 substantial & 65 & 12.2 \\
Traditional schedule & 1 minimal & 22 & 40.7 \\
$\mathrm{~N}=54$ & & & \\
& 2 partial & 14 & 25.9 \\
& 3 sufficient & 8 & 14.8 \\
& 4 substantial & 10 & 18.5 \\
Trimester 2/3 & 1 minimal & 8 & 38.1 \\
$\mathrm{~N}=21$ & & & \\
& 2 partial & 8 & 38.1 \\
& 3 sufficient & 2 & 9.5 \\
& 4 substantial & 3 & 14.3 \\
\hline
\end{tabular}

percentage of students, who scored each of the four CRT scores was separated by the three schedule types. Only $60812^{\text {th }}$-grade students took the Algebra CRT. Table 26 displays scores in each CRT scoring category. For the first time a grade level achieved a higher percent of passing than the previous grade level. By schedule type the passing percentages were: A/B block (33.8\%), traditional (33.2\%), and trimester 2/3 (23.8\%).

Table 27 displays the $t$ test comparisons between schedule types for $12^{\text {th }}$-grade students. In order to determine if there was a statistically significant difference between the CRT scores by schedule type a two-tailed $t$ test for independent samples was conducted. The values generated were comparisons between the three schedule types used by $12^{\text {th }}$-grade students and display the $t$ statistic of the comparisons and the significance as a $p$ value. 
Table 27

Independent t Tests Comparing Percentages for12th Grade for All Schedule Types

\begin{tabular}{llrr}
\hline $\begin{array}{l}\text { Percentage of passing by schedule } \\
\text { type (score of } 3 \text { or } 4)\end{array}$ & $\begin{array}{c}\text { Schedule types: Comparison } \\
\text { of passing scores }\end{array}$ & $t$ statistic & $\begin{array}{c}\text { Two-tailed } \\
\text { significance }\end{array}$ \\
\hline A/B Block $=33.8$ & Block to traditional & .043 & .9659 \\
Traditional $=33.3$ & Block to trimester 2/3 & .467 & .6409 \\
Trimester $2 / 3=23.8$ & traditional to trimester 2/3 & .405 & .6892 \\
\hline
\end{tabular}

Table 27 reveals the results of the $t$ test comparisons for $12^{\text {th }}$-grade students. None of the comparisons for any of the schedule types showed any statistically significant differences. This suggested that students on any schedule type do not have statistically significant relationships with higher scores on the CRT. However, the number of students who took the CRT in $12^{\text {th }}$ grade, when separated by schedule type, was small and called into question the power of the statistical conclusion. The CRT scores for those taught on the $\mathrm{A} / \mathrm{B}$ block schedule and those on the traditional schedule are almost identical for each of the four CRT scores (1-4).

A multinomial logistic regression analysis was conducted to determine the relationship between Utah Algebra I CRT scores, grade level, and the school schedule types in which the students were taught. In total, 46,790 cases were analyzed and the test of the full model against a constant only model was statistically significant, indicating that both predictor variables (schedule type and grade level), as groups, were reliably distinguished among the four different CRT scores (chi square $=571.8, p<.0005$ with $d f$ $=9$ for schedule type and chi square $=1.079 \mathrm{E} 4, p<.0005, d f=15$ for grade level). The overall pseudo- $R^{2}$ Nagelkirke's $R^{2}$ of .284 indicated a moderate relationship between 
predictors and CRT scores for the entire model. $\operatorname{Exp}(B)$ values ranged from .523 to 362.46 when the CRT score of 1 was the reference category. This range of $\operatorname{Exp}(\mathrm{B})$ values indicated, in some instances, no statistical significance for some grade level comparisons of CRT scores by schedule type and, in some cases, a significant different for some grade level comparisons of CRT scores by schedule type.

The multinomial logistic regression analysis yielded the percentage of students, from each grade and from each schedule type who scored a 1, 2, 3 or 4 on the CRT. An independent samples two-tailed $t$ test was conducted between the four schedule types for each grade level. The $t$-test method was selected in order to separate grade levels and schedule types. The statistical comparison was between passing scores on the Algebra I CRT, which simplified the test statistics and greatly simplified the understanding of the $t$ statistic by reducing the number of comparisons. The $t$-statistic comparisons in each grade level, for each schedule type, resulted in a variety of results that are summarized in Table 28.

Table 28 simplified and summarized some of the findings of the preceding 15 tables. The complexity of including so many variables in the study resulted in multilayered conclusions. Overall, higher scores were recorded by students in the lower grades, there was a significant difference in the scores when only considering schedule type, and there was a variety of results when comparing separate grade levels and schedule types. 
Table 28

Summary of Independent Samples t Tests of CRT Scores when Disaggregated by Schedule Type and Grade Level

\begin{tabular}{|c|c|c|}
\hline Grade level & $\begin{array}{c}\text { Passing percentage by schedule type: } \\
\text { Highest to lowest }\end{array}$ & $\begin{array}{l}\text { Significance level between } \\
\text { groups }\end{array}$ \\
\hline 7 & $\begin{array}{ll}1^{\text {st }}: & \text { Trimester } 3 / 3(N=84) \\
2^{\text {nd }}: & \text { Traditional }(N=2,398) \\
3^{\text {rd }}: & \text { Block } \mathrm{A} / \mathrm{B}(N=858)\end{array}$ & $\begin{array}{ll}1^{\text {st }} \text { to } 2^{\text {nd }}: & p=.062 \\
2^{\text {nd }} \text { to } 3^{\text {rd }}: & p=.051 \\
1^{\text {st }} \text { to } 3^{\text {rd }}: & p=.026\end{array}$ \\
\hline 8 & $\begin{array}{ll}1^{\text {st }}: & \text { Trimester } 3 / 3(N=1,451) \\
2^{\text {nd: }}: & \text { Block A/B }(N=4,919) \\
3^{\text {rd }}: & \text { Traditional }(N=9,775)\end{array}$ & $\begin{array}{ll}1^{\text {st }} \text { to } 2^{\text {nd }}: & p<.005 \\
2^{\text {nd }} \text { to } 3^{\text {rd: }}: & p<.005 \\
1^{\text {st }} \text { to } 3^{\text {rd }}: & p<.005\end{array}$ \\
\hline 8 & $\begin{array}{ll}1^{\text {st }}: & \text { Trimester } 3 / 3(N=992) \\
2^{\text {nd }}: & \text { Traditional }(N=7,217) \\
3^{\text {rd }}: & \text { Block A/B }(N=6,799)\end{array}$ & $\begin{array}{ll}1^{\text {st }} \text { to } 2^{\text {nd }}: & p<.005 \\
2^{\text {nd }} \text { to } 3^{\text {rd }}: & p<.005 \\
1^{\text {st }} \text { to } 3^{\text {rd }}: & p<.005\end{array}$ \\
\hline 10 & $\begin{array}{ll}1^{\text {st }}: & \text { Traditional }(N=915) \\
2^{\text {nd }}: & \text { Block A/B }(N=8,404) \\
3^{\text {rd. }}: & \text { Trimester } 2 / 3(N=472)\end{array}$ & $\begin{array}{ll}1^{\text {st }} \text { to } 2^{\text {nd }}: & p<.005 \\
2^{\text {nd }} \text { to } 3^{\text {rd: }}: & p=.312 \\
1^{\text {st }} \text { to } 3^{\text {rd }}: & p<.005\end{array}$ \\
\hline 11 & $\begin{array}{ll}1^{\text {st }}: & \text { Traditional }(N=85) \\
2^{\text {nd. }}: & \text { Block A/B }(N=1,694) \\
3^{\text {rd. }}: & \text { Trimester } 2 / 3(N=76)\end{array}$ & $\begin{array}{ll}1^{\text {st }} \text { to } 2^{\text {nd }}: & p=.004 \\
2^{\text {nd }} \text { to } 3^{\text {rd: }}: & p=.264 \\
1^{\text {st }} \text { to } 3^{\text {rd: }}: & p=.027\end{array}$ \\
\hline 12 & $\begin{array}{ll}1^{\text {st }}: & \text { Block A/B }(N=533) \\
2^{\text {ndd }}: & \text { Traditional }(N=54) \\
3^{\text {rd }}: & \text { Trimester } 2 / 3(N=21)\end{array}$ & $\begin{array}{ll}1^{\text {st }} \text { to } 2^{\text {nd }}: & p=.966 \\
2^{\text {nd }} \text { to } 3^{\text {rd }}: & p=.689 \\
1^{\text {st }} \text { to } 3^{\text {rd }}: & p=.641\end{array}$ \\
\hline
\end{tabular}




\section{CHAPTER V}

\section{DISCUSSION}

The first four chapters of this study contained an introduction of the study's purpose and guiding questions, a review of pertinent literature, a discussion of the methodology and procedures, an analysis of the data, and the report of the results. This chapter includes a summary of the study, a discussion of the results, limitations, recommendations, and conclusions.

\section{Summary}

The purpose of this study was to investigate the relationship between secondary school schedule types and students’ scores on end-of-level Algebra I tests. Specifically, this study explored the relationship between schedule types in Utah schools and the results of the State Algebra I end of level criterion referenced test for the 2010-2011 school year. The relationships were examined in terms of Algebra I CRT scores for all students as a group and then by disaggregation of students' individual grade levels. The potential value of the findings was to inform secondary school administrators and educators of the relationship between schedule types and Algebra I CRT scores and provide research data for decision-making options concerning schedule types.

The research questions were: (1) What is the relationship between mathematics instructional schedule type and student scores on Utah’s CRT for Algebra I, for all students? and (2) What is the relationship between mathematics instructional schedule type and student scores on Utah’s CRT for Algebra I, by individual grade levels? Data 
were collected from the Utah State Office of Education, from 39 school districts, from over 300 individual secondary schools, and included the CRT scores of 46,790 Utah Algebra I students. The statistical methods used to analyze the data were multinomial logistic regression and two-tailed independent sample $t$ tests for percentages. Data analysis was conducted using SPSS software.

\section{Discussion of the Results}

After the relevant data were collected and analyzed the following results were pertinent to the two research questions. The first research question, which examined the relationship between mathematics instructional schedule type and student scores, found that there were statistically significant differences between students on different schedule types with regard to their scores on the Algebra I CRT. The second research question, which examined the relationship between mathematics instructional schedule type and student scores after the students' scores were disaggregated by grade level, found that the greatest differences on students’ CRT scores were after the students’ scores were compared by separate grade levels. Also, with regard to the second research question, the research found that there were some significant differences within some individual grade levels when examining the relationship between mathematics instructional schedule type and Algebra I CRT scores within each separate grade level.

\section{Research Question 1: Results of the Comparisons of Schedule Types for All Grades}

The results for research question 1 showed that a comparison of all students in the 
study indicated significant differences in CRT scores when students were separated by schedule type. With no consideration of grade levels, the passing rates were the highest for students who were taught on the trimester 3/3 schedule (81\%), followed by the traditional schedule (70\%), the block schedule (49\%), and the trimester 2/3 schedule (25\%). One explanation for this result was that all students throughout Utah were not equally distributed into mathematics classrooms that utilized each of the schedule types. This uneven distribution placed more students on the trimester $3 / 3$ schedule who were in seventh, eighth, and ninth grades — the grades in which the highest scores occurred. The total number of students who were taught Algebra I on the block or traditional schedules $(43,685)$ greatly outnumbered the total number of students who were taught on either of the trimester schedules $(3,105)$. The greater number of students on the traditional or block is consistent with schools in other states (Flynn et al., 2005; Geerstle \& French, 1993). The trimester $3 / 3$ schedule was utilized frequently by students in the $7^{\text {th }}-, 8^{\text {th }}-$, and $9^{\text {th }}-$ grade levels, but only nine students in $10^{\text {th }}$ and $11^{\text {th }}$ grades combined were taught on the trimester 3/3 schedule. Generally, high schools tend to have more course offerings than middle schools and have graduation requirements that are more easily met by the traditional or block schedules.

The first result showing statistically significant differences in CRT scores may be explained by the time structure of the trimester $3 / 3$ schedule. In the trimester $3 / 3$ schedule students were enrolled in Algebra I for all three trimesters of the school year. This means that students spent approximately 180 days in mathematics classes each school day for $60-70$ minutes. That would be the greatest amount of time (180-210 hours) spent in the 
mathematics class compared to any other schedule type (see Table 1). The time spent in the classroom on the trimester 3/3 schedule was every day of the school year. The statistically significant result may reflect the benefits of daily interactions within the mathematics classroom with less time between class periods. Conversely, students in the trimester $2 / 3$ schedule and the block schedule spent the least amount of yearly time in the mathematics classroom (140 and 132 hours, respectively). On the widely used block schedule students met every other day. The extra day between class sections may have affected students' mathematical retention. The additional time a student spends in a mathematics class has been shown to be a factor in higher achievement (Adelman \& Pringle, 1995; Fuligni \& Stevenson, 1995; Zepeda \& Mayers, 2006). What is important about this first result is that the amount of overall time spent in an Algebra I classroom for the school year has a statistically significant relationship to higher CRT scores and the time spent is determined by schedule type.

\section{Research Question 2: Results of the Comparisons of Schedule Types for Separated Grade Levels}

The result for the first analysis for research question 2 showed that students in the lowest grade level (seventh grade) scored the highest on the Algebra I CRT and each subsequent grade level had a lower passing rate. The percentage of students who passed the Algebra I CRT was the highest in the seventh grade (95.7\%) but decreased for each subsequent grade level: $8^{\text {th }}$ grade $(80.7 \%), 9^{\text {th }}$ grade $(52.8 \%), 10^{\text {th }}$ grade $(31.7 \%)$, and $11^{\text {th }}$ grade $(24.0 \%)$, with a slight upsurge in $12^{\text {th }}$ grade $(33.4 \%$; see Table 12$)$. This important result indicated that age was a significant factor in determining scores on the Algebra I 
CRT. Many students are administered some form of a prognostic test to determine readiness for Algebra I and this test can be a strong predictor of success (Flexer, 1984). In Utah, most students take Algebra I in seventh or eighth grade for the first time. Therefore, the second result of this study may have been caused by the selection of stronger mathematics students who were algebra-ready students in the lower grade levels. The process of using prognostic test results for student selection means students who were taking the Algebra I CRT in later grade levels were not as algebra ready and not as strong mathematics students (Betts, Hayn, \& Zau, 2011; Bitter \& O’Day, 2010). This study included CRT results for students who have taken the Algebra I course more than once, which would show up as CRT results in the later grade levels. When a student has confidence and interest in mathematics then that student is more likely to be successful. But when a student has to retake a course then that confidence, and interest, is reduced (Koller, Baumert, \& Schnabel, 2001). The better mathematics students easily pass the Algebra I CRT in seventh or eighth grade and, from my 20 years of teaching mathematics, students who struggle early in mathematics or who repeat the course tend to be placed in Algebra I later and are more likely to struggle.

Another important aspect of the result with regard to separate grade levels was that none of the four schedule types solely were related to the highest CRT scores for all of the grades. The schedule types refer to the time allotment for students in the mathematics classroom and do not account for differences in instruction. For example, the students on the trimester $3 / 3$ had the highest scores for seventh, eighth, and ninth grades; students on the traditional schedule had the highest scores for $10^{\text {th }}$ and $11^{\text {th }}$ grade; 
and students on the A/B block had the highest scores for $12^{\text {th }}$ grade. Some of these differences were not statistically significant (see Table 28). This result suggests that no one schedule type had an exclusive relationship to higher CRT scores and that different schedule types may be better suited for different grade levels and students of different achievement levels. However, as noted, the trimester 3/3 schedule was utilized only in the earlier grades and the block and traditional schedules were utilized more frequently in the later grades. The exception to the common occurrence of the trimester $3 / 3$ only being used in earlier grade levels was one high school, which had the only nine students in Utah on the trimester $3 / 3$ schedule who were in $10^{\text {th }}$ or $11^{\text {th }}$ grade.

Students on the trimester 2/3 schedule scored the lowest each time that schedule was used but only 569 students among the 46,790 students in this study were taught on the trimester $2 / 3$ schedule. This result may reflect the limited time the students who are taught on the trimester $2 / 3$ schedule spend in the mathematics classroom during the course of a full school year and the possibility that some students were finished with their Algebra I class months before taking the Algebra I CRT. What is important overall about the results connected to separated grade levels is a realization that differences in CRT scores have a relationship to the grade level of the students. The earlier the grade level the higher the CRT scores tended to be. In addition, the differences in CRT scores for the earliest grades were not significant and no schedule type had a relationship to higher CRT scores for all grade levels. 


\section{Research Question 2: Results of the Comparisons of Schedule Types by Individual Grade Levels}

For the second analysis for research question 2, an examination of the data compared schedule types within separate grade levels. In seventh grade the three schedule types utilized by students had passing rates of 100\%, 96\%, and 94\% (see Table 17). The result of this very high passing rate may have been caused by the overall mathematics ability of the students placed into Algebra I in seventh grade. The results for eighth-grade students, and each subsequent grade level, on the Algebra I CRT were more widely distributed. This may have occurred because, starting in eighth grade, all students are placed in Algebra I and a naturally occurring variety of students’ abilities, instruction methods, and schedule types produced a variety of CRT score results. In the $9^{\text {th }}$ - through $11^{\text {th }}$-grade levels students who were taught on the traditional schedule scored significantly higher than students taught on the block schedule (see Tables 21-25). The reason for this result may have been the allocation of time differences: students on the traditional schedule meet every school day and students on the block schedule meet every other day. The results of the present study counter many of the arguments and research results presented in defense of the block schedule (Ellis, 2004; Gruber \& Onwuegbuzie, 2001; Trenta \& Newman, 2002). While other research on the block schedule has shown an increase in student achievement, using various metrics, the present study suggests that for high school students the block schedule does not yield higher Algebra I CRT scores for students in Utah. Schedule types with a daily Algebra I class had a statistically significant relationship to higher CRT scores. 
The third result showed that $12^{\text {th }}$-grade students scored higher than $11^{\text {th }}$-grade students, which was the only instance in which students in a later grade level scored higher than students in an earlier grade level. One possible explanation for this result is the now-or-never nature of $12^{\text {th }}$ grade with its graduation requirements. Students who have struggled academically, and have not dropped out of high school, may find themselves retaking Algebra I as $12^{\text {th }}$ graders and needing that specific credit for graduation. The third result is important because it suggests that external forces, such as needed credit for graduation, could have been enough of a motivating factor to change the trend of diminishing scores of the earlier four grade levels.

A fourth result which came from the combination of all three findings was the higher scores for students on the trimester 3/3 schedule. More students in earlier grade levels were taught on the trimester $3 / 3$ schedule, and virtually no students after $9^{\text {th }}$ grade were taught on the trimester 3/3 schedule. Students in earlier grade levels scored higher on every schedule type but the lack of the trimester $3 / 3$ schedule in later grades leaves a missing component in the comparison of the same schedule types and CRT scores for all grade levels. The fourth result is important because it suggests that the trimester $3 / 3$ schedule may be the schedule type which would yield the highest Algebra I CRT scores for $9^{\text {th }}$ - through $12^{\text {th }}$-grade levels.

\section{Additional Findings from the This Study}

The collection and organization of the data revealed interesting information about the structures and options that exist within secondary schools in Utah. Many schedule type options exist for schools yet 93\% of all students in the Algebra I classroom were 
taught utilizing the block or traditional schedule. The $4 \times 4$ block schedule is used commonly in other states (Zepeda \& Mayers, 2006; Zhang, 2001) but no school in Utah utilized that schedule in this study. Together the trimester 3/3 schedule and the trimester 2/3 schedule were used in only $7 \%$ of the Algebra I classrooms. As was noted above, the trimester3/3 schedule yielded the highest CRT scores but was only used in the sevenththrough ninth-grade levels.

School administrators are aware of the multifaceted nature of secondary schools. Algebra I is just a single course within a wide variety of course offerings. School counselors must consider the requirements of graduation that entail courses from many core curricular areas as well as elective coursework for students. For some administrators, teachers, students and parents additional time in the mathematics classroom is seen as beneficial but to others the time takes away from options in other core areas or from desired electives (E. Evans, personal communication, March 26, 2012). However, the pressure to comply with NCLB standards, a growing parental view of the value of mathematical understanding, and the potential for merit pay attached to student achievement in specific curricular areas has led some schools to consider adjusting their structures to increase students’ achievement in mathematics (Bitter \& O’Day, 2010; E. Evans, personal communication, March 26, 2012).

\section{Limitations, Recommendations, and Final Conclusions}

\section{Limitations}

This study was very specific in the populations and factors examined and, 
therefore, the results cannot be intended for educational communities and structures outside the study's scope. To have included all possible factors and measures within this study would have been problematic and not focused on the matters of interest to the researcher.

This study was conducted in Utah and, like any state, the state's educational system may have had organizational structures, teacher training programs, and student population attributes which make the transfer of results uncertain to other locations. Mathematics is a particular piece of the entire school curriculum and results from this study should not be assumed to match possible results in other curricular areas. The schedule types examined are consistent with schedule types of the same names elsewhere but some schedule types (hybrid, block $4 \times 4$ ) were not examined in this study. The measure of success or achievement for this study was students' Algebra I CRT scores which is a confining quantum and should not be considered to be the only, or best, measure of student achievement. Within the study's comparison of schedule types there was an unevenness of the distribution. Not all schedule types were present in each grade level which makes assumptions about a better overall schedule type impossible.

\section{Recommendations}

The research brought to light results which lead to the following recommendations for educators. Considerations of schedule type for Algebra I students should be approached with specific deliberation given to the grade levels of the students. No schedule type alone is the panacea for student success. The results of this study showing varied student achievement on the Algebra I CRT suggests students in the 
earlier grades achieve high scores with several schedule types but students in the later grade levels tended to score higher when taught on a schedule type which ensures more time and more frequent classroom contact. Students in high school should have daily, inschool contact with their mathematics curriculum. Even with existing high school graduation requirements, scheduling variations ought to be put in place which maximize the amount of time spent in the mathematics classroom. As the present study reveals, the block schedule, as currently constituted, may be advantageous for several curricular areas (woodshop, photography, and physical education) but appears to have some grade level specific limits with regard to high school mathematics success for students taking the Algebra CRT. Hybrid schedules can allow some classes to meet for longer periods of time every other day but also allow the preferred daily meeting for algebra students.

Changes made to a school's schedule type for algebra should be research based and include quality teacher training. Care should be given to not just teach the previous curriculum with the previous methods and fit them into new and different time structures. Mathematical problem solving for our information age should be a focus within the classroom. A return to the pedagogy or content of the past is not implied by this study. To adequately include problem solving instruction and student practice sufficient time is required and should be incorporated into the school schedule structure. Some schools have undertaken steps to ensure that mathematics students have sufficient time that supports the acquisition of mathematical understanding. One Utah high school, which utilizes the block schedule for all classes, has used a math lab for some students which enable an additional block period with a mathematics instructor for tutoring and 
homework time. Elective, not mathematics, credit is given to students who successfully complete the course. One Utah middle school, which also utilizes a block schedule, has students in their mathematics class every day for an 88 minute time period. The success of these types of programs should be researched further to determine effectiveness.

\section{Final Conclusions}

This study found significant differences with Algebra I CRT scores when comparing grade levels and schedule types. The separation of student data into separate grade levels and then into separate schedule types for this study was somewhat unique in the research. The common metric of the identical Algebra CRT for all 46,790 students in the study made for a statistically powerful analysis. This study followed on the heels of other studies which utilized varying measures of student success to compare different schedule types.

School districts and individual schools have been under increasing pressure to improve specified measures of educational success (Flynn et al., 2005; Gullatt, 2006). Schools have sought educational structures and pedagogical methods to optimize student learning. One of the structures that had been considered is how classroom time is allocated and the uses of various schedule types in the classroom (Canady \& Rettig, 1993; Copple et al., 1992; Geerstle \& French, 1993; Jenkins et al., 2002; Zepeda \& Mayers, 2006). The selection of the block schedule for schools, either the $4 \mathrm{x} 4$ block or the A/B block, has become commonplace with at least $40 \%$ of American secondary public schools using a block schedule by 1995 (Gruber \& Onwuegbuzie, 2001; Flynn et al., 2005; Gullatt, 2006; Zhang, 2001). 
The success of particular schedule types, in terms of student learning, has been researched extensively with mixed results (Table 2). The determination of what is meant by student learning or success has been varied. When the measure was algebra students’ self-efficacy, the block students scored higher (Biesinger et al., 2008); when measuring daily attendance and suspension rate of students, no significant difference was found between schedule types (Deuel, 1999); when measuring end of level scores for core subject matters, students instructed on the block schedule scored higher than those on the traditional schedule (Gruber \& Onwuegbuzie, 2001; Lawrence \& McPherson, 2000); and when measuring Algebra I end of level tests in North Carolina both Ellis (2004) and Zhang (2001) found statistically significant differences in terms of schedule type, with students taught on the block schedule scoring higher.

While this study was broad in the amount of data analyzed, there were still some additional aspects of the topic that could be better studied in the future. If possible, the removal from the data of those students who had previously taken the Algebra I CRT may be insightful. At the time of this study the only available option for data acquisition placed all students within each school who took the Algebra I CRT together and there was no mechanism available for separating repeat test takers. As charter schools increase the number of students the inclusion of these schools into the data set would be of benefit. Charter schools are public schools, as discussed earlier, but since the inception of this study the number of schools and the number of students has increased to the point of being statistically viable. In addition, the adoption of the common core curriculum for mathematics in Utah will eliminate the course title of Algebra I. The transition to the 
common core curriculum will necessitate changes in classroom structures and teacher training but the actual curriculum in the current Algebra I course will not be replaced to any great extent. However, the common core curriculum assessment will most likely be different from the current Algebra I CRT and further study of student results within that new assessment would be very beneficial.

The results of this study suggest that students in the earlier grades achieved higher scores than students in the later grades. Some schedule types had a significant relationship to higher Algebra I CRT scores; schedule types which allowed more time in the mathematics classroom and a daily mathematics class tended to have higher scoring students. This means that school districts and school personal can use this information to make decisions concerning possible schedule types. Matching a particular schedule type, or hybrid type, with individual grade levels may support students’ acquisition of mathematics content and knowledge. 


\section{REFERENCES}

Adelman, N., \& Pringle, B. (1995). Education reform and the uses of time. The Phi Delta Kappan, 77(1), 27-29.

Arbaugh, F., Herble-Eisenmann, B., Ramirez, N., Knuth, E., Kranendock, H., \& Quander, J. (2009). Linking research and practice: NCTM research agenda conference report. Washington, DC: National Council of Teachers of Mathematics.

Arnold, D. E. (2002). Block schedule and traditional achievement: A comparison. NASSP Bulletin, 86, 42-53.

Bass, H. (2005). Review of the 4th grade and 8th grade algebra and functions on NAEP. Retrieved from http://www.brookings.edu/gs/brown/algebraicreasoning.htm

Betts, J., Hayn, Y., \& Zau, A. (2011). Does diagnostic math testing improve student learning? San Francisco, CA: Public Policy Institute of California.

Biesinger, K., Crippen, K., \& Muis, K. (2008). The impact of block scheduling on student motivation and classroom practice in mathematics. North American Society for Social Philosophy, 92, 191-208.

Bitter, C., \& O’Day, J. (2010). Raising expectations for mathematics instruction in California: Algebra and beyond. Sacramento, CA: California Collaboration on District Reform.

Burke, M., Erickson, D., Lott, J., \& Obert, M. (2001). Navigating through algebra in grades 9-12. Reston, VA: The National Council of Teachers of Mathematics.

Canady, R., \& Hothkiss, P. (1985). Scheduling practices and policies associated with increased achievement for low achieving students. Journal of Negro Education, 54, 344-355.

Canady, R., \& Rettig, M. (1993). Unlocking the lockstep high school schedule. Phi Delta Kappan, 75, 310-314.

Carraher, D. W., \& Schliemann, A. D. (2007). Early algebra and algebraic reasoning. In F. Lester (Ed.), Second handbook of research on mathematics teaching and learning (pp. 669-705). ReSton, VA: National Council of Teachers of Mathematics.

Chen, C.-K. (2005). Analyzing student learning outcomes: Usefulness of logistic and Cox regression models. Association for Instructional Research, 5, 2-20. 
Chen, C.-K., \& Hughes, J. (2004). Using ordinal regression model to analyze student satisfaction questionnaires. Association for Institutional Research, 1, 1-13.

Cobb, R., Abate, S., \& Baker, D. (1999). Effects on students on a 4X4 junior high school block scheduling program. Education Policy Analysis Archives, 7(3), 1-23.

Cohen, J., Cohen, P., West, S., \& Aiken, L. (2003). Applied multiple regression/ correlation analysis for the behavioral sciences ( $3^{\text {rd }}$ ed.). New York, NY: Erlbaum.

Copple, C., Kane, M., Levin, D., \& Cohen, S. (1992). National education commission on time and learning. Washington, DC: Pelavin.

Deuel, L. (1999). Block scheduling in large, urban high schools: Effects on academic achievement, student behavior, and staff perceptions. The High School Journal, 83, 14-25.

Ellis, G. H. (2004). A comparison between selected 4x4 block schedule schools and seven-period traditional schools as measured by the public schools in North Carolina end-of-course tests in algebra and biology. Fayetteville, NC: University of North Carolina.

Flexer, B. (1984). Predicting eighth-grade algebra achievement. Journal for Research in Mathematics Education, 15, 352-360.

Flynn, L., Lawrenz, F., \& Schultz, M. (2005). Block scheduling and mathematics: Enhancing standards-based instruction. North American Society for Social Philosophy, 89, 14-23.

Forman, E. (2009). Increase percentage of passing grades on the Massachusetts comprehensive assessment system after implementation of block scheduling. Lowell, MA: University of Massachusetts.

Fuligni, A., \& Stevenson, H. (1995). Time use and mathematics achievement among American, Chinese, and Japanese high school students. Child Development, 66, 830-842.

Garson, D. (2011). Logistic regression. Retrieved from http://faculty.chass.ncsu.edu/ garson

Geerstle, L., \& French, D. (1993). Structuring schools for student success: A focus on instrumental change. Boston, MA: Massachusetts State Department of Education.

Glenberg, A., \& Andrzejewski, M. (2008). Learning from data: An introduction to statistical reasoning. New York, NY: Erlbaum. 
Gravetter, F., \& Wallnau, L. B. (2005). Essentials of statistics for the behavioral sciences. Belmont, CA: Wadsworth.

Gruber, C., \& Onwuegbuzie, A. (2001). Effects of block scheduling on academic achievement among high school students. High School Journal, 84, 32-42.

Gullatt, D. E. (2006). Block scheduling: The effects on curriculum and student productivity. North American Society for Social Philosophy, 90, 250-266.

Haas, M. (2005). Teaching methods for secondary algebra: A meta-analysis of findings. North American Society for Social Philosophy, 89, 24-46.

Hancock, D., Mattox, K., \& Queen, A. (2005). The effect of block scheduling on middle school students' mathematics achievement. North American Society for Social Philosophy, 89, 3-13.

Howard, E. (1997). Block scheduling and advanced placement mathematics: When tradition and reform collide. American Secondary Education, 26, 13-16.

Jenkins, E., Queen, A., \& Algozzine, B. (2002). To block or not to block: That's not the question. The Journal of Educational Research, 95, 196-202.

Kieran, C. (2007). Learning and teaching algebra at the middle school through high school. In F. K. Lester (Ed.), Second handbook of research on mathematics teaching and learning (pp. 707-762). Reston, VA: National Council of Teachers of Mathematics.

Kliebard, H. M. (2004). The struggle for the American curriculum. New York, NY: Rutledge.

Koller, O., Baumert, J., \& Schnabel, K. (2001). Does interest matter? The relationship between academic interest and achievement in mathematics. The Journal for Research in Mathematics Education, 32, 448-470.

Lakoff, G., \& Nunez, R. (2000). Where mathematics comes from: How the embodied mind brings mathematics into being. New York, NY: Basic.

Lawrence, W. W., \& McPherson, D. D. (2000). A comparative study of block scheduling and traditional scheduling on academic achievement. Journal of Instructional Psychology, 27, 78-82.

Lewis, C., Dugan, J. J., Winokur, M. A., \& Cobb, R. B. (2005). The effects of block scheduling on high school academic achievement. North American Society for Social Philosophy, 89, 72-86. 
National Commission on Excellence in Education. (1983). A nation at risk: The imperative for educational reform. Washington, DC: U.S. Government Printing Office.

National Council of Teachers of Mathematics. (2008). Algebra: What, when, and for whom? Reston, VA: Author.

National Education Commission on Time and Learning. (1994). Prisoners of time: Report of the national education commission on time and learning. Washington, DC: Author.

Queen, A. J. (2009). The block scheduling handbook. Thousand Oaks, CA: Corwin.

Rosario, J. (2000). Communitarianism and the moral order of schools. In B. M. Franklin (Ed.), Curriculum \& consquence: Herbert M. Kliebard and the promise of schooling (pp. 30-51). New York, NY: Teachers College, Columbia University.

Schoenfeld, A. H. (2002). Making mathematics work for all children: Issues of standards, testing, and equity. Educational Researcher, 31, 13-25.

Sizer, T. (1992). Horace's school: Redesigning the American high school. Boston, MA: Houghton Mifflin.

Spencer, W., \& Lowe, C. (1994). The use of block periods for instruction: A report after two years. Nashville, TN: Mid-South Educational Research Association.

Thomas, E., \& Galambos, N. (2004). What satisfies students? Mining student-opinion data with regression and decision tree analysis. Research in Higher Education, 45, 251-269.

Trenta, L., \& Newman, I. (2002). Effects of a high school block scheduling program on students: A four year longitudinal study on the effects of block scheduling on student outcome variable. American Secondary Education, 31, 54-71.

UCLA Statistics. (2007). Introduction to SAS. Retrieved from http://www.ats. ucla.edu/stat

Utah State Office of Education. (2008). Testing web site. Retrieved from http://www.schools.utah.gov/computerservices/Meetings-October

Utah State Office of Education. (2010). Graduation information. Retrieved from http://www.schools.utah.gov/curr/gradinfo/

Utah State Office of Education. (2011a). Education graduation information. Retrieved from http://www.schools.utah.gov/CURR/gradinfo?High-SchoolRequirements.aspx 
Utah State Office of Education. (2011b). Educational directory. Retrieved from http://www.schools.utah.gov/default/directory.pdf

Utah State Office of Education. (2012). Utah criterion-referenced test 2008-2011. Retrieved from http://www.schools.utah.gov/Assessment-Student-AchievementUtah_Criterion-Referenced2008-2011

Veal, W. R., \& Flinders, D. J. (2001). How block scheduling reform effects classroom practice. The High School Journal, 84, 21-31.

Wronkovich, M., Hess, C., \& Robinson, J. (1997). Repudiation, reinvention, and educational reforms. Educational Administration Quarterly, 35, 292-304.

Zepeda, S. J., \& Mayers, R. S. (2006). An analysis of research on block scheduling. Review of Educational Research, 76, 137-170.

Zhang, G. (2001). Academic performance differences between students in block and traditionally scheduled high schools. Washington, DC: American Educational Research Association. 
APPENDICES 
Appendix A

Institutional Review Board (IRB) Certificate 


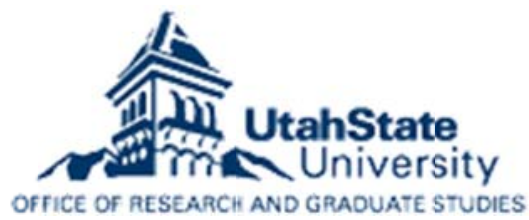

Institutional Review Board

USU Assurance: FWA\#00003308

Exemption \#4

Certificate of Exemption

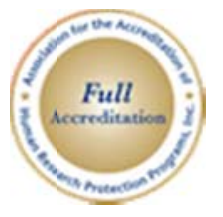

From: $\quad$ Richard D. Gordin, Acting IRB Chair True M. Rubal, IRB Administrator

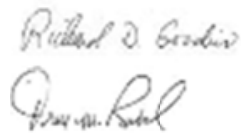

To: $\quad$ Patricia Moyer-Packerham, Gregory Murrah

Date: $\quad$ March 01, 2012

Protocol \#: 4299

Title: $\quad$ Scheduling Variations: Achievement in the Algebra I Classroom

The Institutional Review Board has determined that the above-referenced study is exempt from review under federal guidelines 45 CFR Part 46.101(b) category \#4:

Research, involving the collection or study of existing data, documents, records, pathological specimens, or diagnostic specimens, if these sources are publicly available or if the information is recorded by the investigator in such a manner that subjects cannot be identified, directly or through identifiers linked to the subjects.

This exemption is valid for three years from the date of this correspondence, after which the study will be closed. If the research will extend beyond three years, it is your responsibility as the Principal Investigator to notify the IRB before the study's expiration date and submit a new application to continue the research. Research activities that continue beyond the expiration date without new certification of exempt status will be in violation of those federal guidelines which permit the exempt status.

As part of the IRB's quality assurance procedures, this research may be randomly selected for continuing review during the three year period of exemption. If so, you will receive a request for completion of a Protocol Status Report during the month of the anniversary date of this certification.

In all cases, it is your responsibility to notify the IRB prior to making any changes to the study by submitting an Amendment/Modification request. This will document whether or not the study still meets the requirements for exempt status under federal regulations.

Upon receipt of this memo, you may begin your research. If you have questions, please call the IRB office at (435) 797-1821 or email to irb@usu.edu.

The IRB wishes you success with your research. 
Appendix B

Permission to Publish State of Utah Data 
To Whom it May Concern:

The Utah State Office of Education (USOE) grants permission to Gregory Murray, a distance doctoral student at Utah State University and faculty member of Dixie State College, to appropriately use State data provided for him. The data are 2010-2011 Algebra I CRT scores for all students in Utah who took, and have recorded, that particular State Algebra I exam.

The data will be used for his doctoral dissertation. The data will not contain specific student or teacher names but proficiency scores aggregated by school. Permission is not given to reveal the names or other identification of any individual student or teacher. If a school has ten or fewer students who took the Algebra test then that school will not be included in the research.

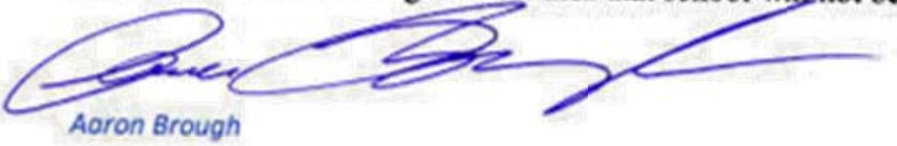

Educational Doto Specialist

USOE Assessment Dato Steward

Utoh State Office of Education

SLC, Utah 84114

(801)538-7922 
Appendix C

Descriptors of Terms for Algebra I Proficiency Scores 


\section{Algebra I Proficiency Scores}

\section{Minimal (1)}

Students performing at the minimal level are beginning to apply their algebra mathematics skills. They are learning how to represent and compute with most rational and some irrational numbers. They have limited ability to manipulate or solve linear equations Students simplify monomials and some polynomials, but have difficulty with factoring. They inaccurately model representations of linear equations using tables, graphs, or equations. Students may attempt to solve or graph systems of linear equations. Students have difficulty solving quadratic equations. They identify some traits of slope, and begin to understand it as a rate of change. Students summarize two-variable data sets and are developing an understanding of correlation. They estimate lines of best fit with drawings, but cannot write corresponding equations.

\section{Partial (2)}

Students performing at the partial level inconsistently apply their algebra mathematics skills. They represent, define, classify, compute, and estimate most rational and some irrational numbers. They manipulate and solve linear equations and inequalities. Students simplify and may be able to factor monomials, most polynomials, and some quadratic expressions. They model representations of linear equations and some inequalities using tables, graphs, or equations but may not be able to solve, graph, or interpret systems of linear equations or inequalities. They solve basic quadratic equations by factoring or by taking square roots. Students recognize slope as a rate of change but inconsistently determine the slopes of lines. Students summarize, display, and recognize the correlation of two-variable data sets. They estimate lines of best fit, and attempt to interpret and test conjectures.

\section{Sufficient (3)}

Students performing at the sufficient level apply algebra mathematics skills appropriately. They use multiple representations to define, classify, compute, and estimate with rational and irrational numbers. Students manipulate, solve, and extract pertinent information from linear equations and inequalities. They explain the four operations with rational and irrational numbers, and determine reasonableness of results. Students simplify and factor monomials, polynomials, and quadratic expressions. They analyze, connect, and model multiple representations of linear equations and inequalities using tables, graphs, and equations. Students solve, graph, analyze, and interpret systems of linear equations and inequalities with and without technology. They solve quadratic equations by factoring or by taking square roots. They identify, determine, analyze, and apply slope as rate of change. They summarize, display, and analyze the relationship or

correlation of two-variable data sets. They determine and estimate lines of best fit and write equations to interpret and test conjectures. 


\section{Substantial (4)}

Students performing at the substantial level consistently apply algebra mathematics skills appropriately. They fluently represent, classify, compute, and estimate rational and irrational numbers. They effectively manipulate, solve and extract pertinent information from linear equations and inequalities. Students simplify and factor completely monomials, polynomials, and quadratic expressions. They efficiently analyze, connect, and model multiple representations of linear equations and inequalities using tables, graphs, and equations. Students consistently solve, graph, analyze, and interpret systems of linear equations and inequalities with and without technology without difficulty. Students solve quadratic equations using factoring and write quadratic equations when given the solutions. They skillfully analyze and apply slope as rate of change. Students summarize, display, and analyze the relationship and correlation of two-variable data sets and make reasonable predictions. They estimate and write equations for lines of best fit to interpret and test conjectures. 


\section{CURRICULUM VITAE}

\section{GREGORY V. MURRAY}

College of Education

Dixie State College of Utah

225 So. 700 East

St. George, Utah 84770
1790 S. Rockcress Circle

St. George, Utah, 84790

(435) 673 - 6037 (home)

(435) 229 - 9823 (cell)

gvmurray@hotmail.com

\section{Education}

Ph.D. Curriculum and Instruction, Mathematics Education specialization, 2012. School of Teacher Education and Leadership, Utah State University. Dissertation topic: Relationships Between Classroom Schedule Types and Performance on the Algebra I Criterion Referenced Test

Chair: Dr. Patricia Moyer-Packenham, Professor of Mathematics Education. Utah State University

Master of Education, Secondary Education, Utah State University. Professional specialization: Stimulating mathematics in the high school setting. Master's Thesis: Creation of a High School Mathematics Placement Guide. 1992

Bachelor of Arts, History \& Secondary Education (double major), Mathematics minor University of Montana, Missoula, Montana 1987. magna cum laude

\section{Teaching Experience}

\section{Instructor and Secondary Teacher Placement Director (June 2010 - present) Department of Education, Dixie State College, St. George, Utah}

Introduction and Foundations of Education (EDUC 1010)- The course is for students pursuing a degree in the teaching profession. Provides an overview of vocational aspects of a teaching career including: certification requirements, foundations of education, current and historical issues in education, and an overview of current trends in methodology. This class provides students with an opportunity to assess oneself as a prospective teacher.

Secondary Teaching Methods (SCED 4700)- This course is for students in the Secondary Education Teachers Program during the semester prior to student teaching. Provides instruction for students with various secondary teaching majors. Included topics: 
differentiated instruction, classroom procedures, professional organizations, varied instructional techniques and educational legal issues.

Capstone Course for Student Teachers (SCED 4989) - The course is for student teachers in the field and involves providing feedback to student teachers as well as instruction and guidance in the creation of a resume, Dixie College portfolio and a teacher work sample.

Director of Secondary Student Placement- Responsibilities include coordination and administration of placement of practicum students and student teachers from Dixie College into the Washington County School District. Coordination is between student teachers, classroom mentor teachers, College supervisors, school principals, and school district administration.

Student Teacher Supervisor - Responsibilities include periodic in-school evaluations of student teachers, conferencing with mentor teachers, and continual guidance to practicing student teachers. Formal and informal evaluations and coordination with the capstone instructor become part of the students’ permanent college record.

\section{Classroom Teacher: Mathematics, History, Photography, and Humanities (1989- 2010), Dixie High School, St. George, Utah}

Algebra 1- An introduction to student to variables, algebraic expressions, equations, functions, inequalities, and their graphical representation. Developments of the students' ability to explore and solve mathematical problems, think critically, work cooperatively with others, and communicate mathematical ideas.

Geometry -The courses includes an in-depth analysis of plane, solid, and coordinate geometry as they relate to both abstract mathematical concepts as well as real-world problem situations. Topics include logic and proof, parallel lines and polygons, perimeter and area analysis, volume and surface area analysis, similarity and congruence, trigonometry, and analytic geometry. Emphasis is placed on developing critical thinking skills as they relate to logical reasoning and argument while using different technological tools and manipulatives to discover and explain much of the course content.

Algebra II- A continuation of Algebra I with continued explorations of linear functions, quadratic functions, inequalities and their various representations. Additional topics include trigonometric functions, matrices, probability and statistics.

Photography -State of Utah visual arts endorsement. The course includes basics elements of the film camera including f/stops, aperture, and shutter speeds; lenses, films and lighting. Included are the artistic aspects of photographic composition, rendering light, balance, rule of thirds, and artistic expression. 
Hawthorne Junior High, Hawthorne, Nevada 1987- 1989. Seventh- and eighth-grade mathematics.

\section{Professional Presentations}

Murray, G. (April 2006). St. Louis, Missouri. NCTM Annual Conference. CrossCurriculum Instruction in the Mathematics Classroom.

Murray, G. (April 2002). Las Vegas, NCTM Annual Conference. Theoni Pappas Grant Recipient: You Can Too.

Murray, G. (November 2001). San Juan School District, Blanding, Utah. Geometry for Everyone. Presentation to the San Juan School District mathematics teachers.

Murray, G. (1996 -2001). Washington County School District. Math Night. Presented multiple times to other Washington County mathematics teachers.

Murray, G. (May 2000). Chicago, NCTM Annual Conference. Modular Arithmetic Meets the Matrix.

Murray, G. (April 1999). San Francisco, NCTM Annual Conference. Modular Arithmetic Meets the Matrix.

Murray, G. (June 1998). Cedar City, Utah. Geometry Vision. Co-designer and copresenter for week long summer workshop for Utah version of national Geometry Vision workshops.

Murray, G. (July 1997). Princeton University, Institute of Advanced Studies. Statistics for All Occasions. Co- instructor for sixty mathematics teachers from around the U.S.

\section{Professional Development and Service}

\section{Research Coursework and Research Interest}

Utah State University: Research and Models in Reading; Current Issues and Theories of Mathematics Education; Critical Theory in Education; Theory and Practice of Qualitative Research; Theory of Curriculum Design; Quantitative Research Analysis and Design; Educational Leadership

\section{Professional Conferences and Workshops}

Professional Learning Communities Conference, Richard DuFour, Los Angeles, October 2007. 
National Council of Teachers of Mathematics (NCTM) Annual Conferences: 2006, 2002, 2000, 1999, 1998, 1994, 1991. Regional Conferences: 2003, 1992, 1989, 1987.

T-Cubed Technology Conference, Las Vegas, 2002.

Utah Council of Teachers of Mathematics (UCTM) 1996, 1994

The Conference of Restructuring Schools, Phoenix, 1994.

\section{Photography}

Solo Exhibition: Dixie State College Eccles Foyer Gallery, Points of View. Summer 2012

Artist-in-Residence: Rocky Mountain National Park (2001, summer).

Printed Publications: The Spectrum Newspaper, 2012. National Geographic (online) 2010, 2009, 2008, 2007. Utah State University Aggie Calendar: 2009. Peterson's Photographic: 2000.

Arts Festivals: St. George Arts Festival (2002-2005). Park City Arts Festival (2002, 2001) Magnificent Mile Art Show (Chicago) (2001). Utah Arts Festival (2000, 1999).

Project Manager for SURWEB. A U.S. Department of Education program to photograph and document the natural resources in Utah $(1996$ - 2001).

Museum Exhibits: Zion National Park Centennial, Springdale, Utah (2009). Zion National Park Centennial, St. George, Utah (2009). BYU Art Museum (2006). St. George Museum (2005) solo show: Spacious, the Great Salt Lake. St. George Museum: The Regional Exhibit (1999- 2002). State of Utah Biennial, traveling show.

Photography Website: www.gregmurrayphotography.com

\section{Professional Development}

MathCounts, (2005 - 2008). National mathematics item writer for math competition program. Worked with a team from across the U.S. in the creation of challenging math explorations and questions for MathCounts.

National Board Certification for Mathematics (2002). Attained certification through National Board for Professional Teaching Standards (NBPTS) in Middle Years Mathematics. 
Hinkeley Institute of Politics (1998). University of Utah. Graduate of the Institute which investigated current public policies in Utah in relation to culture.

N.C.T.M. Theoni Pappas Grant Award (1995). The only recipient that year for a project which created a connection between subject areas for use in the mathematics classroom. The project was entitled: Cross-Curriculum Integration of Mathematics and Photography.

Geometry Vision (1995-1998). Presenter and curriculum writer for the Utah off- shoot of Regional Geometry Institute of Princeton, New Jersey. N.S.F. funding.

Teacher-in-Residence, Institute of Advanced Studies (1997) Princeton, New Jersey. An application accepted position for the summer session of a mathematics gathering of two hundred mathematics high school teachers, university graduate students, and university faculty. My topic infused into the program was stretching probability in the high school mathematics classroom.

Teacher-in-Residence, Institute of Advanced Studies (1996) Park City, Utah. An application accepted position for the summer session of a mathematics gathering of two hundred mathematics high school teachers, university graduate students, and university faculty. My topic for that summer session was multiple representations, multiple views.

Regional Geometry Institute (1993-1995). Park City, Utah and Princeton, New Jersey. The program is a part of the Institute of Advanced Studies in Princeton New Jersey. Participation in a gathering of mathematics teacher and students with the goal of improving mathematics education from middle school through university.

\section{School Service}

Professional Educators Coordination Committee, Dixie State College, 2010- present STEM Committee Member, Dixie State College, 2011- present

Instructor in mathematics, history, financial literacy, and photography, 1989 - 2009.

National Honor Society advisor, 1999- 2008.

State of Utah Core Curriculum co-writer 1993 - 1994

Mathematics department chair, 1993-1995, 2003-2005.

Academic academy director, 1994.

Cooperative learning in-service presentations, 1992.

\section{Affiliations}

National Council of Teachers of Mathematics 1990 to present.

Utah Council of Mathematics Teachers 1990-1998.

Utah Education Association 1990-2008. 